\title{
Unique stable isotope signatures of large cyclonic events as a tracer of soil moisture dynamics in the semiarid subtropics
}

\author{
Grzegorz Skrzypek ${ }^{1}$, Shawan Dogramaci ${ }^{1,2}$, Gerald F.M. Page ${ }^{1}$, Alexandra Rouillard ${ }^{1}$, \\ Pauline F. Grierson ${ }^{1}$
}

1. Ecosystems Research Group and West Australian Biogeochemistry Centre, School of Biological Sciences, The University of Western Australia, Perth 6009, WA, Australia

2. Rio Tinto Iron Ore, Perth, WA, Australia

*corresponding author: grzegorz.skrzypek@uwa.edu.au,gskrzypek@yahoo.com 


\section{Abstract}

Evaporative flux from soils in arid and semi-arid climates can be very high and may substantially reduce soil moisture retained between infrequent rainfall events. Direct measurement of the evaporative losses from soils is technically challenging; however, environmental tracers such as stable hydrogen and oxygen isotope composition can be used to calculate evaporation rates if the initial signature of the infiltrating rainwater is distinct from the signature of residual soil moisture. Large tropical cyclones typically result in rainfall events of large volume and very negative $\delta^{18} \mathrm{O}$ signatures that are significantly lower than the signatures of the usual precipitation. These very negative stable isotope signatures are retained in the soil and can be used to understand the depth of water infiltration, retention and subsequent rate of evaporation from the soil. At our study site in dry subtropical northwest Australia, we repeatedly sampled rainwater and soil moisture prior to, during and after tropical cyclones Heidi and Lua in 2012. Site inundation from Cyclone Heidi (rainfall $213 \mathrm{~mm}, \delta^{18} \mathrm{O}$ $17.6 \%$ ) replenished soil moisture in the unsaturated zone for several months, completely replacing soil moisture down to depths of $\sim 3.5 \mathrm{~m}$ and contributing to groundwater recharge. The transient momentary evaporative losses from wet soil at the time of sampling (recalculated as an annual rate) varied between 76 and $220 \mathrm{~mm} \times \mathrm{yr}^{-1}$. During the prolonged dry period between cyclones, evaporative losses decreased to between 8 and $30 \mathrm{~mm} \times \mathrm{yr}^{-1}$. Consequently,

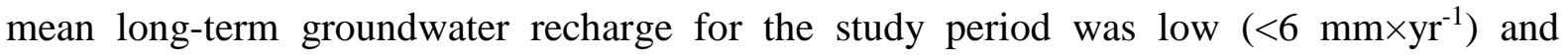
primarily driven by infrequent but high-volume cyclones that are an important source of soil moisture and therefore an essential water source for vegetation in the semi-arid environment. However, upscaling from a local to a regional scale model for ecological water demand would be challenging due to the high variability in $\delta^{18} \mathrm{O}$ observed in soil profiles, which varies with lithology, position in the landscape and time since the last inundation. 


\section{Introduction}

Soil moisture dynamics drive landscape hydrological regimes and determine water availability to ecosystems depending on the dominant evapotranspiration regime (Seneviratne et al. 2010; D’Odorico et al., 2012; Nicholson, 2000). Globally, direct evaporation from the soil ( 20 \%) and plant transpiration ( 40 \%) return most terrestrial precipitation to the atmosphere, while the remaining $40 \%$ contributes to groundwater recharge and runoff (Oki and Kanae, 2006). Some of the previous studies suggest even higher transpiration fluxes (Jasechko et al., 2013; Schlesinger and Jasechko, 2014) but with possibly with much higher uncertainty (Coenders-Gerrits et al., 2014). However, in arid and semi-arid climates, terrestrial evaporative flux is more substantial, even approaching $100 \%$ in extreme conditions (e.g., in terminal basins; Skrzypek et al., 2016), which in turn limits runoff and recharge. In the arid tropics in particular, groundwater recharge occurs only occasionally, mostly in response to highly episodic tropical cyclones (TCs) or monsoonal low pressure systems (Abdalla and AlAbri, 2011; Dogramaci et al. 2015; Eastoe et al., 2015; Müller et al., 2016; Meredith et al., 2018). These large and intense but generally infrequent rainfall events also replenish soil moisture in the vadose zone and are recognised as critically important for the maintenance and functioning of ecosystems (Bowman et al., 2010; Kam et al., 2013; Khouakhi et al., 2017). However, there have been a few direct observations of soil moisture dynamics in the unsaturated vadose zone in arid and semi-arid environments (e.g., Dubbert et al., 2013; Gaj et al. 2016; Oerter and Bowen, 2017). The quantification of evaporative loss from unsaturated soils remains a serious constraint to precise quantification of water budgets globally (e.g. Akbar and Gianotti 2018Gaj et al., 2016). In particular, there have been very few direct observations of infiltration depths of differing rainfall events, especially in dryland regions (Abdalla and Al-Abri, 2011; Rossi et 
al., 2018). Infiltration depth associated with large rainfall events will likely be shallower when occurring after long dry periods than after the soil has been recently wetted. This occurs, in part, because wetting and drying cycles profoundly influence soil permeability and the capacity for water retention, particularly in clay-rich soils (Sprenger et al., 2017; Tollenaar et al., 2017). Therefore, soil moisture replenishment and groundwater recharge depend not only on the rainfall volume but also on the frequency of cyclonic rainfall and the antecedent soil moisture content.

Similarly, soil water losses are affected by soil texture and mineralogy, vegetation including variable rooting depths among plant species, as well as climate conditions. The rate of evaporative water loss from the soil profile is governed by the depth of the boundary at which the vapour flux is greater than the liquid water flux. The position of this boundary is determined by the distribution of soil moisture across the profile, as driven by the infiltration depth (e.g. Tollenaar et al., 2017). Individual soil dry-down characteristics for any given site will thus be different and reflect varying atmospheric and vegetation conditions. Direct measurement of evaporative loss from soils and the variation in this loss with depth must account for large uncertainties in estimation of local water fluxes, and with partitioning evaporation from transpiration (e.g. Bakhtiari et al., 2010; Dijkema et al., 2017; Stumpp and Maloszewski, 2010). One approach is to use stable isotope techniques for indirect quantification of the evaporative loss of water from soils under field conditions (Gaj et al., 2016, 2019; Oerter and Bowen, 2017). The stable isotope composition of soil moisture has also been used to trace water movement in the unsaturated zone (Barnes and Allison, 1988), as well as to estimate groundwater recharge (Allison et al., 1983, 1984, 1988; Cane and Clark, 1999; Sprenger et al. 2017). Thus, stable isotope methods are ideally suited for studying the dynamics of moisture in the unsaturated zone across wetting and drying events. 

have focussed on characterising isothermal and non-isothermal unsaturated zone processes, on trying to explain both steady-state and non-steady-state evaporation (see the recent review by Koeniger et al., 2016) or on quantification of the total evaporative loss from the top 50-100 cm of soil only (Gaj et al., 2016; Hasselquist et al., 2018; Haverd and Cubtz, 2010). Even though soils with unsaturated zones of 5-20 m are common, very few stable isotope profiles have been characterised at depths beyond 2 m (Barenes et al., 1988; Soderberg et al., 2011; Sprenger et 2016; Akbar and Gianotti 2018).

In the present study, we sought to estimate the contributions of large volume and highintensity rainfall events to soil moisture in the semi-arid north-western region of Australia and to obtain a better understanding of the persistence and dynamics of rainwater in the soil profile during intervening dry periods. We first characterised the regional patterns in rainfall volumes and stable isotope compositions associated with two major cyclones, as well as several minor rainfall events, over a three-year period. Given that cyclone-associated rainfall tends to be highly ${ }^{18} \mathrm{O}$-depleted, primarily due to a massive rainout effect and convection (e.g. Dogramaci et al., 2012; Guan et al., 2013; Mook et al., 1974; Zwart et al., 2018), we expected that the stable oxygen isotope signatures $\left(\delta^{18} \mathrm{O}\right.$ values) of different cyclones following different paths across the continent would result in rainfall that carries a distinctive 'negative isotopic fingerprint’ (e.g., Good et al., 2014; Lawrence and Gedzelman, 1996, 1998; Zwart et al., 2016). We, therefore, hypothesised that the signatures of different cyclone events would be discernible in soil moisture profiles and that we could capture the infiltration depth of each event. We sampled the unsaturated zone for soil moisture and the water stable oxygen isotope composition 
to gain an understanding of the patterns in soil moisture variability across the landscape after a

127 prolonged drought. We then made repeated measures of profile responses to subsequent wetting and drying to estimate the cyclonic rainwater contribution to soil moisture and its retention time thereafter. We used these analyses as a context for interpreting temporal patterns in infiltration and evaporation after extended drought following recharge events aiming to understand soil moisture budget in a dry and warm climate where likely recharge is primarily driven by cyclonic events. to the study, the last known flood was in 2006 (Wallace and Devereux, 2013). The extent of

\section{Materials and methods}

\subsection{Study site and regional context}

The study site was located within a topographic depression ( 705 m asl, $\sim 170 \mathrm{ha}$ ) at the base of Mount Bruce (1,234 m asl), in the Hamersley Ranges of the Pilbara region of northwest Australia. The site is located within Karijini National Park adjacent to the Marandoo mine site (Fig. 1). Vegetation overlaying deeper soils in the depression is open woodland dominated by Eucalyptus victrix L.A.S. Johnson \& K.D. Hill (Coolibah) trees with a tussock grass understorey, but which transitions sharply to mulga (Acacia aptaneura Maslin \& J.E. Reid) woodland on the shallow soil boundaries (Fig. 1). The site is an ephemeral wetland and sits within an internally draining basin where surface flows originate from direct rainfall and local surface runoff from the surrounding mountain ranges formed from low permeability formations (Brockman and Marra Mamba Iron Formations). Anecdotally, the woodland is known to flood only rarely, once or twice a decade and has no permanent surface water. Prior the flooded area in 2006 was $\sim 8 \mathrm{~km}^{2}$ and surface water persisted for around 89 days. The groundwater table is $\sim 18 \mathrm{~m}$ bgl (below ground level) and within the depression is overlain by 
deep soils comprised primarily of colluvium containing red/brown colluvial clay and gravel with calcrete and dolocrete horizons down to $\sim 12 \mathrm{~m}$ bgl and dolocrete horizons with some clays below this depth.

The climate is hot with mean, maximum and minimum annual temperatures of $23.5^{\circ} \mathrm{C}$, $31{ }^{\circ} \mathrm{C}$ and $17^{\circ} \mathrm{C}$, respectively (Tom Price; 1997-2011, site 5072). Mean annual precipitation is $380 \mathrm{~mm}$ (Marandoo mine site; 2005-2016; www.bom.gov.au, site 5074). The mean potential annual pan evaporation $(\sim 3,000 \mathrm{~mm})$ is approximately an order of magnitude greater than the average rainfall (www.bom.gov.au, site 005026). Most rainfall ( 85 \%) occurs during the cyclone season in the austral summer from December to March. However, the frequency and intensity of cyclones vary unpredictably both seasonally and among years (Rouillard et al., 2015). Groundwater recharge across the Hamersley Basin is primarily associated with highvolume rainfall events (Dogramaci et al., 2012). Annual recharge via main drainage lines can range from $<1 \mathrm{~mm} \times \mathrm{yr}^{-1}$ to $13 \mathrm{~mm} \times \mathrm{yr}^{-1}$ based on estimates made using ${ }^{14} \mathrm{C}$ dating and $\mathrm{Cl}$ mass balance calculations (Cook et al., 2016). However, at many sub-catchments recharge is estimated to be less than $5 \mathrm{~mm} \times \mathrm{yr}^{-1}$, reflecting large regional differences in rainfall distribution, geomorphology, and lithology (McFarlane, 2015).

\subsection{Soil sampling - the baseline for dry condition}

Soils were first sampled for moisture content and water stable isotope composition between $5^{\text {th }}$ and $20^{\text {th }}$ November 2010 using a sonic drilling system that allowed drilling without water using vibration and ultrasound (Boart Longyear ${ }^{\mathrm{TM}}$ LS 600 SONIC DRILL, head BL150). This first sampling occurred in one of the driest years on record (Rouillard et al., 2015), when only $7 \mathrm{~mm}$ of rainfall had fallen in the preceding 6 months (Fig. S1). Soils were sampled from ten locations along a transect across the woodland to capture variation in underlying lithology, soil depth and surface topography at the site (bores CB01-C10, Fig. 1). All 
unsaturated soil profiles were sampled to a maximum depth of $\sim 17 \mathrm{~m}$ once. Soil temperature was monitored, samples were collected immediately from each core and sealed into $50 \mathrm{~mL}$ preweighed tins for soil moisture and in $150 \mathrm{~mL}$ Parafilm sealed vials for the soil moisture stable oxygen isotope composition.

In addition to soil moisture, groundwater was also sampled from the piezometers installed in the selected locations adjunct to the study site. Groundwater was collected using an MPI pump, by first pumping out at least three volumes of the bore or until EC, $\mathrm{pH}$ and oxygen concentrations were stable to ensure that bores were sufficiently purged. All water samples were sealed in $20 \mathrm{~mL}$ glass vials and stored at $5^{\circ} \mathrm{C}$ until analyses on Picarro 1115-i system.

The stable isotope and soil moisture concentrations on the $1.6 \mathrm{~km}$ long cross-sections were prepared based on 159 data points and interpolated using Point Kriging with linear variogram (Slope 1, Anisotropy 1, 0) using Golden Software Inc. Surface Mapping System Surfer 13.6. (Golden, Colorado, USA) (Goldsztejn and Skrzypek, 2004).

\subsection{Assessment of responses of the soil profile to rainfall inputs from large events}

Owing to logistical and cost constraints that precluded access to the recently inundated sites, it was not possible to re-sample using a sonic drill rig. Thus, to investigate soil responses to wetting and subsequent drying, we sampled soils at $\sim 20 \mathrm{~cm}$ intervals to a depth of $4 \mathrm{~m}$ from the lowest position in the woodland (CB05) with a manual auger (Fig. 1). The manual augering was conducted on 23 February 2012, approximately 6 weeks after TC Heidi (12 January 2012) and again on 17 May 2012 (to a depth of 5 m) after TC Lua (17 March 2012). A final sampling of surface soils was conducted on 12 November 2013 (to a depth of $\sim 2 \mathrm{~m}$ ). Soils during this last sampling were extremely hard set and it was not possible to hand auger to greater depths.

\subsection{Rainwater sampling}



at the Hope Downs weather station, $110 \mathrm{~km}$ SE from the focus study site. Composite rainfall samples were collected at the end of each month over a one-year period between February 2011 and January 2012 (Fig. 2). These data were used to establish the Local Meteoric Water Line (LMWL), which was then used to verify the deviation of the cyclone stable isotope signature from usual long-term precipitation (Fig. 2). In addition, an informal professional network of hydrologists, hydrogeologists, and environmental scientists working at several mine sites at eight locations across Pilbara region of Western Australia collected rainwater samples during two major cyclones; Heidi (9-13 January 2012) and Lua (17 March 2012). Rainwater was collected at one to three-hour intervals for the duration of each cyclone event (Fig. 3). Cyclone paths were obtained from the Australian Bureau of Meteorology (BoM) Tropical Cyclone Database (www.bom.gov.au/cyclone/history). The spatial patterns of associated rainfall were developed using a $250 \mathrm{~km}$ radius buffer from daily cyclone tracks based on $0.05 \times 0.05^{\circ}$ resolution daily rainfall grids of the BoM (Jones et al., 2009; www.bom.gov.au/climate/austmaps/about-rain-maps). To match with the daily rainfall observations, the nearest daily position, i.e., TC progress as of 9:00 am was used. All processing of spatial data was conducted in ArcView, and the layers were converted to Geographic Datum Australia 1994 and projected onto the national Map Grid of Australia zone 50 (Fig. 4).

\subsection{Soil moisture, chloride, and stable isotope analyses}

Gravimetric soil moisture content (\%), pre and post-cyclone event, was determined for all soil samples. Fresh soil samples were weighed in the laboratory and oven-dried at $105^{\circ} \mathrm{C}$ for 5 days (or until constant weight) before being reweighed. Volumetric soil moisture content 
could not be calculated as the soil structure could not be preserved during the sonic nor auger drilling process.

The stable hydrogen and oxygen isotope composition $\left(\delta^{2} \mathrm{H}\right.$ and $\left.\delta^{18} \mathrm{O}\right)$ of water and soil moisture were analysed using an Isotopic Liquid Water Analyser Picarro L1115-i with a V1102-I vaporiser (Picarro, Santa Clara, California, USA) at the West Australian Biogeochemistry Centre (Skrzypek and Ford, 2014). Raw $\delta^{2} \mathrm{H}$ and $\delta^{18} \mathrm{O}$ values of the samples were normalized based on three laboratory standards calibrated against international reference materials (Skrzypek, 2013) provided by the International Atomic Energy Agency that determine the VSMOW2-SLAP2 scale (Coplen, 1996).

Soil moisture $\delta^{18} \mathrm{O}$ and $\delta^{2} \mathrm{H}$ were analysed using the vapour headspace equilibration method modified after Wassenaar et al. (2008). Approximately 50-100 mL of soil sample was transferred to $0.5 \mathrm{~L}$ Ziploc ${ }^{\mathrm{TM}}$ bag filled with dry ultra-high purity nitrogen and sealed. The samples were equilibrated with headspace gas to achieve saturation over $72 \mathrm{hrs}$ at $23^{\circ} \mathrm{C}$. Three laboratory soil moisture stable isotope standards and one control standard were analysed with each batch of soil samples. The soil moisture stable isotope standards were prepared using a sub-sample of field collected soil that was oven dried at $110{ }^{\circ} \mathrm{C}$, before liquid water laboratory standards of known stable isotope composition were injected into $120 \mathrm{~mL}$ vials filled with dry soil and kept at a constant temperature of $23^{\circ} \mathrm{C}$ for $72 \mathrm{hrs}$. Soil standards were then transferred and equilibrated in Ziploc ${ }^{\mathrm{TM}}$ bags the same way as samples following the principle of the identical treatment. The combined analytical uncertainty (one standard deviation) for soil moisture samples was $<0.30 \%$ for $\delta^{18} \mathrm{O}$ and $<4.0 \%$ for $\delta^{2} \mathrm{H}$. Due to large uncertainty of $\delta^{2} \mathrm{H}$ analyses and potential susceptibility for secondary effect as reported by Hendry et al. (2015), in this study, $\delta^{18} \mathrm{O}$ was used to describe spatial and temporaries changes in soil moisture stable isotope composition. The liquid rainwater and groundwater samples were analysed using the same laboratory standards as soil samples measured using equilibration, with all samples and 
standards were analysed and directly as liquid water on a Picarro L1115-I, with analytical uncertainty $<1.0 \%$ o for $\delta^{2} \mathrm{H}$ and $<0.10 \%$ for $\delta^{18} \mathrm{O}$.

The concentrations of chloride anions $\left(\mathrm{Cl}^{-}\right)$in groundwater samples were analysed by SGS laboratories Australia Pty. Ltd. in Perth, Western Australia, utilising Discrete Analyser Aquakem DA (method ref. APHA 4500).

\subsection{Calculation of evaporative loss using isothermal evaporation model}

The evaporative losses from an unsaturated soil profile were quantified using the isothermal evaporation model summarized by Allison et al. (1988) (Eq. 1) where the depth of the evaporative front and its stable isotope composition is related to soils parameters.

$\begin{array}{lr}\delta=\delta_{\text {res }}+\left(\delta_{0}-\delta_{\text {res }}\right)^{\exp \left(-z /\left(\mathrm{z}_{1}+z_{v}\right)\right.} & \text { Eq. } 1 \\ z_{1}=D^{* / E} & \text { Eq. } 2 \\ Z_{v}=\left(\alpha \times \sigma \times D^{*} \times N\right) /(E \times p) & \text { Eq. } 3\end{array}$

where $D^{*}$ is the effective diffusivity of the pore water, reflecting soil tortuosity, and varies usually between $1.5 \times 10^{-9}$ to $2.3 \times 10^{-9} \mathrm{~m}^{2} \mathrm{~s}^{-1}$ (Mills, 1973)

$Z$ - depth coordinate below the evaporative front, positive downwards (m)

$E$ - evaporation $\left(\mathrm{mm} \times \mathrm{yr}^{-1}\right)$

$N$ - water density

$p$ - density of liquid water

$\alpha$ - temperature-dependent equilibrium fractionation factor $\left(\sim 0.99\right.$ for $20-40{ }^{\circ} \mathrm{C}$ )

$\sigma-$ humidity dependent kinetic fractionation factor ( 4 at RH $70 \%$ )

$\delta_{0}-\delta^{18} \mathrm{O}$ of the evaporative front

$\delta_{\text {res }}-\delta^{18} \mathrm{O}$ of the source water, e.g. water in the aquifer 


\section{Results}

3.1. Spatial variation in soil moisture and stable isotope composition of the unsaturated zone after a prolonged drought

Based on the drilling profiles, topsoils at the site are chromosols, and the lithology consists of red/brown colluvial clay up to $\sim 12 \mathrm{~m}$ thick, with varying amounts of ironstone gravel. This horizon often becomes more bleached with depth, with pods of cream/light brown hard impure calcretes and dolocretes. Below the colluvial clay, there was a calcareous horizon up to 10 m thick, where clay soils are interspersed with lenses of cream and light brown dolocrete. A well-developed white and cream hard crystalline dolocrete layer was located in the central part of the cross-section (bores CB03, CB05, and CB06, Fig. 1). In November 2010, the groundwater table was observed at $\sim 18 \mathrm{~m}$ below the ground surface and $3 \mathrm{~m}$ below the deepest sediment sampling point (position CB05). At 20 m bgl, the dolocrete transitioned into hard red/brown clays with variable amounts of gravel resembling reddish-brown clays.

At the initial sampling in November 2010, conducted during a prolonged dry period (Fig. S1), the soil moisture content and stable oxygen isotope composition were highly variable, both vertically and horizontally (Figs. 5, 6 and S2). As might be expected, the soils were extremely dry at the surface (between 8 and $13 \%$ w/w at $0.4 \mathrm{~m}$ ). Low moisture contents were also observed in the low porosity dolocrete layers that occurred at greater depths (min. $\sim 4.6 \% \mathrm{w} / \mathrm{w}$ ), including the large dolocrete clast in the central part of the cross-section $\sim 8 \mathrm{~m}$ below CB05 and CB06 (695 m asl, $13 \%$ w/w). The highest moisture contents (16-18 \% w/w) were found in the colluvium at $\sim 5$ to $\sim 8 \mathrm{~m}$ below the surface (698 $\mathrm{m}$ asl, Fig. 5). The wettest colluvium was located beneath the lowest positions in the landscape, and this horizon was continuous between sampling positions CB03 and CB08 (Figs. 1, 5). The highest soil moisture 
content measured during the dry period ( $19 \%$ w/w) was at $~ 12 \mathrm{~m}$ below CB05, which coincides with the lowest point in the landscape and the lithological contact between the colluvium and solid dolocrete layers (691 m asl, at Fig. 5).

The stable oxygen isotope composition of soil moisture was largely decoupled from the soil moisture content and its distribution with depth and across the landscape (Fig. 5 and 6). The highest $\delta^{18} \mathrm{O}$ values were observed at the edge of the Coolibah Woodlands with the mulga (CB01-CB04) and the highest elevations (>1\%o in the top $0.4 \mathrm{~m}$ ). By contrast, the lowest $\delta^{18} \mathrm{O}$ values ( 1 to $-1.5 \%$ o) in the top layer $(<0.4 \mathrm{~m})$ were observed in the central part of the woodland below the lowest position in the landscape (CB05-CB08, Fig. 6). Similarly, the range of the relative soil moisture variation with depth was lowest in the profiles collected at the edge of the Coolibah Woodlands and highest in the central part (Fig. 5). The $\delta^{18} \mathrm{O}$ value of soil moisture progressively decreased (i.e. became more depleted in the heavier ${ }^{18} \mathrm{O}$ isotope) with depth, regardless of the lithological changes. However, the rate of decrease depended on the position in the landscape and the local lithology and therefore decoupled from moisture content. Near the surface low soil moisture content was usually associated with high $\delta^{18} \mathrm{O}$, however, this was not always the case deeper below the ground. Therefore, the pattern of values distribution in Fig 5 and Fig.6 are different. The $\delta^{18} \mathrm{O}$ values of $-9.0 \%$ extended up from the water table to approximately 688-689 $\mathrm{m}$ asl ( 14-17 $\mathrm{m} \mathrm{bgl})$ and were consistent with the stable isotope composition of groundwater in the saturated zone below $685 \mathrm{~m}$ asl (-9.03 $\pm 0.56 \%$ ) and chloride

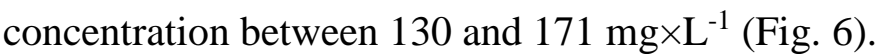

\subsection{Cyclone contributions to the regional surface water budget: tropical cyclones Heidi} and Lua

Two cyclones made landfall in the Pilbara in 2012, each delivering a different volume of rainfall along different paths (Fig. 4). Over the period of six months prior to TC Heidi, only 7 
mm of rainfall were recorded at the study site. The centre of TC Heidi crossed the Pilbara coast at Port Hedland on 11 January at 20:00 (204 $\mathrm{km} \times \mathrm{h}^{-1}$ wind gust, Category 3), and the cyclone eye crossed over the study site (84 $\mathrm{km} \times \mathrm{h}^{-1}$ wind gust) on 12 January 2012 at 18:00 (Fig. 4). The total rainfall over land along the cyclone path in the $250 \mathrm{~km}$ radius from the eye of the cyclone was estimated in our study (see the procedure in 2.4.) at 16,100 GL ( 600 GL on 11 Jan, $\sim 6,800$ GL on 12 Jan and $~ 8,700$ GL on 13 Jan). A total of $\sim 4,700$ GL fell in the Upper Fortescue catchment, causing flooding on the Fortescue Marsh (484 km², $276 \mathrm{GL})$. The highest rainfall inland (232 mm) was observed near the Lower Fortescue Marsh, approximately $60 \mathrm{~km}$ NNE of the study site, and $212 \mathrm{~mm}$ fell at the study site in the western Karijini National Park (Fig. 4). The centre of the second cyclone, TC Lua, made landfall on 17 Mar at 06:00 (222 $\mathrm{km} \times \mathrm{h}^{-1}$ max wind gust; Category 3 ) and reached central Pilbara at 15:00 on the same day ( 150 $\mathrm{km} \times \mathrm{h}^{-1}$ wind gust) along a path $230 \mathrm{~km}$ westward from that of TC Heidi. Similar to TC Heidi, TC Lua delivered a large volume of rain over the landmass (16,600 GL). However, the spatial distribution of rainfall during TC Lua was much more widespread over the NW, while the bulk of the rainfall during TC Heidi was delivered within only $100 \mathrm{~km}$ of the study site (Fig. 4). Specifically, during TC Lua, only 1,100 GL fell in the Upper Fortescue River catchment, with the majority falling in the Lower Fortescue River catchment; by contrast, at the study site, only $33 \mathrm{~mm}$ of rainfall were recorded. This is consistent with TC Lua's maximum estimated mean radius of the outermost closed isobar (ROCI) over land being nearly classified as 'large' (556 km), compared to the 'very small' (185 km) classification for TC Heidi.

The woodland study site was flooded to $<1 \mathrm{~km}^{2}$ in response to TC Heidi, but the exact area could not be calculated due to clouds obscuring Landsat satellite images (Wallace and Devereux, 2013). No surface water expression was evident after TC Lua. High temperatures during the austral summer $\left(27^{\circ} \mathrm{C}\right.$ daily average for the Tom Price weather station) caused a very high evaporation rate and resulted in rapid drying of surface water and shallow soils. The 
regional evaporation rate for March 2012 was estimated at $275 \mathrm{~mm}$ (in the scale of a year corresponding to $3,300 \mathrm{~mm} \mathrm{y}^{-1}$ ), based on the analysis of the satellite pictures showing a progressive reduction of the flood extent of the Fortescue Marsh (Fig. S3).

The massive rainout on the $270 \mathrm{~km}$ path of TC Heidi between the coast and central Pilbara resulted in a significant variation, both spatially and temporally, in the stable isotope composition of rainwater (Fig. 3). Rainwater closer to the coast tended to have less negative values, e.g., Western Creek $\left(50 \mathrm{~km}, \delta^{18} \mathrm{O}=-13.5 \%\right.$ to $\left.-3.6 \%\right)$ and Ti Tree $\left(120 \mathrm{~km}, \delta^{18} \mathrm{O}=\right.$ $10.0 \%$ o, when compared to more inland locations at Yandicoogina $\left(280 \mathrm{~km}, \delta^{18} \mathrm{O}=-12.9\right.$ to $13.6 \%$ ) and the study site $\left(220 \mathrm{~km}, \delta^{18} \mathrm{O}=-13.7\right.$ to $\left.-19.3 \%\right)$. However, the $\delta^{18} \mathrm{O}$ values also varied with the distance from the cyclone centre and the timing of rainfall. The study site, located almost directly in the path of TC Heidi (Fig. 4), received rainfall with the lowest $\delta^{18} \mathrm{O}$ signatures thus far recorded in the Pilbara (min. recorded $-19.3 \%$ ). As a result of the generally more positive values for TC Lua and the larger distance of the cyclone eye from the study site, the $\delta^{18} \mathrm{O}$ values were more positive for the soil moisture contribution from TC Lua. At the rainwater sampling location closest to the cyclone path, Yandicoogina mine $(110 \mathrm{~km}$ from study site westward) varied over time between $0.0 \%$ and $-9.61 \%$ and at the B4 mine - closest to the studied location (90 km East of the study site) varied between -5.0 and $-11.28 \%$ \% (Fig. 3). These extremely low $\delta^{18} \mathrm{O}$ values also resulted in a low weighted-by-volume mean rainfall of $-17.6 \%$ for TC Heidi and $-11.6 \%$ for TC Lua at the study site. The surface floodwater collected at the Coolibah woodland study site ten days after TC Heidi still had very low $\delta^{18} \mathrm{O}$ values, between $-13.4 \%$ and $-16.4 \%$. These extremely low $\delta^{18} \mathrm{O}$ values were consistent with the very negative $\delta$-values of the rainwater collected at the peak of the rainfall during TC Heidi. This suggests that the infiltration had occurred rapidly and the original signature of infiltrating water was preserved in the soil. Defuse recharge and associated high evaporation rates would have resulted in much more positive $\delta^{18} \mathrm{O}$ values. 
3.3. Changes in soil stable isotope composition in response to cyclone-driven rainfalls and subsequent drying

We assessed the contribution of the successive cyclones Heidi and Lua to the soil moisture content by comparing the patterns in soil moisture and stable isotope composition between November 2010 and November 2013 at CB05, the lowest point in the landscape (Fig. 7). In dry conditions, the soil moisture (8 November 2010) was fairly uniform between 1 and $5 \mathrm{~m}$ depth, with a mean of $16.5 \pm 0.4 \% \mathrm{w} / \mathrm{w}$ (Fig. 7), and was similar near the surface $(12.2 \% \mathrm{w} / \mathrm{w}$, $0.4 \mathrm{~m}$ depth). The soil moisture $\delta^{18} \mathrm{O}$ in the top $4-5 \mathrm{~m}$ was also fairly uniform, with a mean value of $-3.7 \pm 0.5 \%$ o (Fig. 8, red line). However, these conditions rapidly changed after TC Heidi occurring between 9 and 13 January 2012 and reflected a very negative $\delta^{18} \mathrm{O}$ of infiltrating floodwater. Six weeks after TC Heidi flooded the site, the soil $\delta^{18} \mathrm{O}$ was very negative, with the highest value of $-6.7 \%$ recorded near the surface and the lowest value reaching $-17.6 \%$ at $\sim 3.5 \mathrm{~m}$ depth. This low $\delta^{18} \mathrm{O}$ value is consistent with rainfall arising from TC Heidi at the site (-17.6 \%) (Fig. 8, blue line). Over the same period, the soil moisture content increased to $29.7 \%$, a value which is approximately equal to the maximum porosity expected for these types of sediment, indicating that the soils were saturated or nearly saturated to a depth of at least $4 \mathrm{~m}$ (Fig. 7, blue line). The second cyclone, TC Lua, modified the $\delta^{18} \mathrm{O}$ value of soil moisture again, and the minimum $\delta^{18} \mathrm{O}$ value of the moisture in the soil core collected 61 days after the cyclone (17/05/2012) was observed at 2 m (-11.6 \%, Fig. 8, green line). This value is consistent with the minimum $\delta^{18} \mathrm{O}$ signatures of TC Lua (-11.3\%) sampled during the peak of the rainfall at the Brockman 4 Mine Site ( $\sim 90 \mathrm{~km}$ to the west of the study site). This change in the stable isotope composition accompanied the soil water content decrease from $29.7 \%$ to 16.2 \% (Fig. 7). At our final sampling in November 2013, the soil stable isotope composition (>-4.25\% in upper $2 \mathrm{~m}$ ) was similar to the initial $\delta^{18} \mathrm{O}$ values 
400

401

402

403

404

405

406

407

408

409

410

411

412

413

414

415

416

417

418

419

420

421

422

423

424

observed in 2010. However, this last observation period also included some rainfall (a few negligible events of $<20 \mathrm{~mm}$ and one of $60 \mathrm{~mm}$ ), which could have contributed to infiltration during the wet summer season of 2012/2013 (Fig. S1).

\section{Discussion}

We were able to resolve the contributions of successive cyclones to soil moisture in the unsaturated zone by utilizing the unique $\delta^{18} \mathrm{O}$ signatures of rainfall associated with each cyclone. The very negative and distinct stable isotope signatures of cyclonic rainfall remained present in the deep soil profile for many months, even under hot and dry conditions, and were used to understand the depth of infiltration, retention and subsequent rate of evaporation from the soil.

\subsection{The range of spatial variation of $\delta^{18} \mathrm{O}$ in the unsaturated zone during dry conditions}

Similar to the range of $\delta^{18} \mathrm{O}$ values observed in this study (-10.5\% to $+8.9 \%$ o), a broad range of $\delta^{18} \mathrm{O}$ values has been reported previously in various soil profiles (e.g. Allison et al., 1984; Gaj et al., 2016). However, none of the previous studies reported results on a sufficiently extensive spatial scale to allow construction of a stable isotope cross-section across the landscape, as conducted in the present study (Fig. 6). In this study, each of the individual $\delta^{18} \mathrm{O}$ profiles (Fig. S2 and S4, appendix) collected after a long dry period displayed typical dryingout curves (Barnes and Allison, 1988). More positive $\delta^{18} \mathrm{O}$ values were recorded closer to the surface and more negative $\delta^{18} \mathrm{O}$ values, comparable to those of groundwater $\left(\delta^{18} \mathrm{O}-9.03 \%\right.$, $\delta^{2} \mathrm{H}-65.9 \%$, d-excess 6.3), were recorded at the depth of 14-17 m ( 689 m asl). A progressive decrease in $\delta^{18} \mathrm{O}$ values with depth was observed along the whole transect, regardless of the local changes in lithology. However, the rate of this decrease with depth varied widely in the 
cores, from $0.28 \% / \mathrm{m}$ to $1.04 \%$ o/m (Fig. S4). Evaporation from the soil profiles differs from that of open water bodies because the free movement of vapours is restricted by the texture of the soil matrix (Gat, 2010). Therefore, the relative differences in the $\delta^{18} \mathrm{O}$ profiles primarily reflect the relative differences in active diffusivity (Allison et al., 1984, 1985), as well as the initial stable isotope signatures of water and the amount of recharge water entering the soils through the preferred infiltration zones.

The most negative $\delta^{18} \mathrm{O}$ values closest to the surface were observed under the alluvial plain between CB06 and CB08, where surface water was most persistent after occasional flooding (Fig. 6). The observed distribution of $\delta^{18} \mathrm{O}$ with depth suggests that the soil moisture remained in a stable isotope equilibrium with the groundwater for up to $\sim 4 \mathrm{~m}$ above the water table in the studied cores (i.e. 14-17 m bgl). The water flux through this section of the profile, mainly driven by physical processes such as the capillary rise or dispersion, was sufficiently high to outweigh the potential impact of ${ }^{18} \mathrm{O}$-enrichment resulting from evaporative flux from the soil in the upper part and d-excess in the bottom part of the soil cores remains high (e.g., 8.6 at CB05; 8.1 at CB04). Therefore, the evaporative loss can be expected to impact $\delta^{18} \mathrm{O}$ only in the top 13-15 $\mathrm{m}$ of the soil profile after eight months of the very dry period in a hot climate. The soil moisture content varied between the saturated bottom parts of the profiles ( $27 \%$ vol) to the very dry soils on the surface $(<5 \% \mathrm{vol})$. However, in contrast to the $\delta^{18} \mathrm{O}$ values, soil moisture content did not show constant increases with depth, and it also varied across the landscape (Fig. 6). Although the water content in the central part of the unsaturated profile between 702 and $694 \mathrm{~m}$ asl (Fig. 5) varied in a relatively narrow range (12-17\%), it primarily reflected differences in the lithology, porosity and position in the landscape rather than the direct evaporative loss or the expected evaporative flux. Therefore, the soil moisture content and its $\delta^{18} \mathrm{O}$ were largely decoupled. Horizontal moisture diffusion and the stable isotope re- 
equilibration were likely negligible and unable to override the differences arising from evaporation and vertical water vapour fluxes, despite a prolonged dry period of eight months.

Regional groundwater recharge can be roughly estimated based on $\delta^{18} \mathrm{O}$ of the soil moisture following the calculation algorithm proposed by Allison et al. (1984) and as presented by Clark and Fritz (1997). This approach has been used in several studies (e.g., Gaj et al., 2016, Walker et al., 1988), despite some methodological concerns (Herczeg and Leaney, 2011; Koeninger et al., 2016). Here, to minimalize the local variability, we used a large regional data set (Dogramaci et al., 2012) for fresh and brackish groundwater from central Pilbara to calculate the water line for groundwater $\left(\delta^{2} \mathrm{H}=6.13 \times \delta^{18} \mathrm{O}-6.47, \mathrm{n}=299\right)$ and the LMWL, as calculated in this study for Hope Down 4 mine site $\left(\delta^{2} \mathrm{H}=7.60 \times \delta^{18} \mathrm{O}+7.76\right.$, Fig. 2$)$, to calculate so-called $\delta^{2} \mathrm{H}_{\text {shift }}$ and $\delta^{18} \mathrm{O}_{\text {shift }}$ (Allison et al., 1984). The estimated regional recharge varied between 1.7 and $2.6 \mathrm{~mm} \times \mathrm{yr}^{-1}$ (average $2.1 \mathrm{~mm} \times \mathrm{yr}^{-1}$ ). However, the method used here did not take into account the evaporative losses from the surface prior to infiltration, and it reflected the evaporative loss from soil only. Despite the hot Pilbara climate (mean annual temperature $23.5^{\circ} \mathrm{C}$, the average for Marandoo based on monthly means over 2005-2013), the mean evaporative losses from the surface prior recharge to groundwater are expected to be relatively low (Skrzypek et al., 2013) but still statistically significant. This is indicated by the statistically significant difference ( $\mathrm{p}$-value $<0.01$ ) between the slope of the groundwater line and the LMWL (Fig. 2). Evaporative losses from the surface water in the range of 17-20\% could entirely explain the observed difference between the $\delta^{18} \mathrm{O}$ of groundwater and rainwater (Skrzypek et al., 2013), without the need to include mixing and evaporation of soil moisture (Allison et al., 1983). Nevertheless, an estimated average recharge rate of $\sim 2.1 \mathrm{~mm} \times \mathrm{yr}^{-1}$ is consistent with the results of a large regional study (McFarlane, 2015) that estimated the average groundwater recharge for Pilbara at $\sim 1.5 \mathrm{~mm} \times \mathrm{yr}^{-1}$, and not exceeding $10 \mathrm{~mm} \times \mathrm{yr}^{-1}$. 

the study site could be much higher than the estimated mean groundwater recharge rate for the

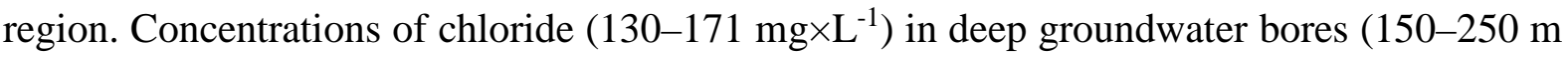
bgl) indicated a recharge rate of between 4.7 and $6.1 \mathrm{~mm} \times \mathrm{yr}^{-1}$, which is within the values estimated for the region by McFarlane (2015). This value was calculated using a simple point scale chloride mass balance (Crosbie et al., 2018), mean annual precipitation of $380 \mathrm{~mm}$ (recorded at Marandoo over period 1999-2016) and a mean $\mathrm{Cl}$ concentration of $2.1 \mathrm{mg} \times \mathrm{L}^{-1}$ observed in rain (72 samples). A potential explanation for these higher recharge rates could be the presence of preferential infiltration paths beneath the ponded water that occurred in the lowest parts of the landscape.

The influence of topography on localized recharge and vertical infiltration is a major factor governing the moisture distribution in the soil across the landscape beside lithology. In in the much more negative $\delta^{18} \mathrm{O}$ values closer to the surface under the alluvial plain between CB05 and CB08 (Fig. 8), where higher infiltration could be expected due to water ponding. In these central locations of the floodplain, the initial soil moisture was likely higher than in the external locations (e.g. CB01, CB02 or CB10). The relative differences in the evaporative losses from individual soil cores can be estimated from the soil drying profile and the vertical change of $\delta^{18} \mathrm{O}$ with the depth. The surface areas in Fig. S4 reflecting the progress of evaporation have been calculated for the triangles drawn between the regression line displaying a change in $\delta^{18} \mathrm{O}$ with depth and the surface (depth $\mathrm{y}=0 \mathrm{~m}$ ) and the mean $\delta^{18} \mathrm{O}$ of groundwater in this location (-9.0\%). The slope of the regression line is increasing as the evaporation from the soil is increasing, and subsequently, soil moisture becomes ${ }^{18} \mathrm{O}$-enriched with depth, therefore, the size of the triangle area (calculated as $\mathrm{m} \times \%$ ), reflects the progress of evaporation 497 from the soil column and the fraction of the total water lost to evaporation. These triangle areas 
in the locations with the expected highest preferential infiltrations (CB06 $17 \mathrm{~m} \times \%$ and CB04 $22 \mathrm{~m} \times \%$ ) and therefore the lowest relative evaporative losses are as much as two to five times lower than at locations outside of the centre of the alluvial plain, which are expected to experience less infiltration and higher relative evaporation (CB01 112 m×\%o, CB02 46 m×\%o, and CB10 $43 \mathrm{~m} \times \%$ ).

The evaporative losses from an unsaturated soil profile can be further quantified using the isothermal evaporation model summarized by Allison et al. (1988) (Eq. 1, 2, and 3). However, major uncertainties arise in the results obtained using this approach when the estimation of soil tortuosity and active diffusivity is difficult. In our study, the lithology was variable with depth and across the landscape. To address this variability, we used values that covered the entire range expected for the type of soils at our site, aiming instead to quantify the range of possible evaporation rates and to compare the relative differences among locations along the transect, rather than to estimate the exact evaporation losses. The total evaporative loss, calculated as $\mathrm{mm} \times \mathrm{yr}^{-1}$ at the time of the sampling after a long dry period, varied between

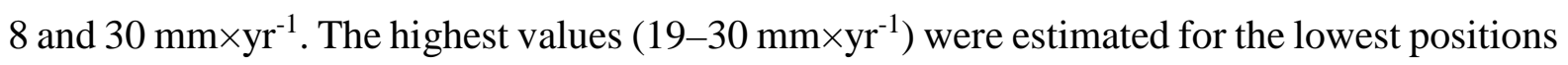
in the landscape (CB06, CB07, and CB08), where more soil moisture was available and could be evaporated. By contrast, the lowest values $\left(8-14 \mathrm{~mm} \times \mathrm{yr}^{-1}\right)$ observed for the driest soils were located at the highest positions in the landscape (CB01 and CB10). These values will remain relatively constant (subject to seasonal variation) if the soil reaches a steady-state and if the values reflect the evaporative flux from the groundwater aquifer. If they still reflect a certain degree of moisture originating from the most recent recharge event, despite a long period since significant rainfall, these values may progressively decrease, as the soil moisture will dry out. These observation based on the isothermal evaporation model are consistent with conclusions based on calculated triangles (Fig. S4). The transects CB01 and CB10 had the lowest residual moisture and the highest $\delta^{18} \mathrm{O}$ values which imply the highest relative evaporative loss 
comparing to the lowest locations (CB06, CB07, and CB08). However, in the term of total

524

525

526

527

water flux at CB06, CB07 and CB08 the total volume of evaporating water likely was higher and relatively much more would need to evaporate to achieve the same relative evaporative enrichment as at CB01 and CB10. Therefore, the size of the triangles reflects the proportional relative evaporative loss of all available water while the isothermal evaporation model shows directly the total water volume lost to evaporation.

\subsection{Spatiotemporal patterns in stable isotope signatures of rainfall associated with cyclones} and their importance for assessing regional water budgets

The extremely negative $\delta^{2} \mathrm{H}$ and $\delta^{18} \mathrm{O}$ values of cyclone rainfall recorded during this study in a semi-arid subtropical region in northwest Western Australia were consistent with the results published for hurricanes from earlier studies in the United States (Gedzelman and Lawrence, 1982; 1990; Lawrence and Gedzelman, 1996) and Australia (Munksgaard et al., 2015; Zwart et al., 2018). Nevertheless, the observed stable isotope composition was far below the typical range of $\delta^{18} \mathrm{O}$ values expected for the studied locations (Dogramaci et al., 2012; Fellman et al., 2011). The major driver of heavy isotope depletion in rainfall has been associated with a massive rainout effect arising from the progressive loss of moisture from clouds and an associated temperature-dependent equilibrium fractionation and convention (Dansgaard, 1964; Zwart et al., 2018). The vapours remaining in the clouds show a depletion of heavy isotopes along the cyclone pathway in proportion to the intensity of the rainfall. The spatial distribution of the stable isotope composition was also consistent with the previously observed gradual decrease in $\delta^{18} \mathrm{O}$ values inward toward the cyclone eyewall (Lawrence and Gedzelman, 1996, 1998). A similar observation was made by Good et al. (2014), who tracked Cyclone Sandy across the eastern part of the US and reported $\delta^{18} \mathrm{O}$ values as low as $-23.3 \%$ 
547 for short time intervals, as well as volume-weighted averages at different distances from the 548 cyclone path that varied between $-6.8 \%$ and $-14.9 \%$. that ranged between -13.7\%o and -19.3\% (TC Heidi at Marandoo), with higher values between $0.1 \%$ and $-9.6 \%$ (TC Lua at B4) with respect to the location of the sampling station in relation to the cyclone path (Fig. 4). The $\delta^{18} \mathrm{O}$ values closer to the cyclone path during TC Heidi (at Marandoo) were more negative when compared with the locations further from the cyclone path during TC Lua (at B4). Although a very large range of $\delta^{18} \mathrm{O}$ values was recorded locally, the mean volume-weighted $\delta^{18} \mathrm{O}$ signatures were close to the most negative values observed during the rainfall event at each location because the most intense rainfall delivering the largest rain volume had the most negative $\delta^{18} \mathrm{O}$ values (Mook et al., 1974). While the stable isotope composition of cyclone-associated rainfall was spatially and temporally variable, the Meteoric Water Lines (MWL) for each cyclone and location (e.g. the MWL for cyclone at Yandicoogina versus the annual LMWL for Hope Downs Fig. 2) did not differ significantly from a MWL based on all cyclone rainwater samples pooled together $\left(\delta^{2} \mathrm{H}=7.5 \times \delta^{18} \mathrm{O}+8.6\right.$ for TC Heidi and $\delta^{2} \mathrm{H}=7.7 \times \delta^{18} \mathrm{O}+11.7$ for TC Lua, Fig. 3). Overall, the slope of the regression for the cyclones was not significantly different from that of the LMWL for Hope Downs $\left(\delta^{2} \mathrm{H}=7.6 \times \delta^{18} \mathrm{O}+7.8\right.$; Fig. 2), which is located $110 \mathrm{~km} \mathrm{SE}$ of the study site. As a result, floodwaters with very negative $\delta^{18} \mathrm{O}$ values but close to the LMWL infiltrated into the soil and eventually contributed to the groundwater. However, the floodwater $\delta^{18} \mathrm{O}$ signatures were significantly more negative than the values observed in the groundwater at this location (-9.03 $\pm 0.56 \%$ o) and in the Hamersley Basin in general (mean -8.0 \% $\pm 1.0 \%$, Dogramaci et al., 2012; Skrzypek et al., 2013), allowing a separation of the cyclone-driven infiltration from the long-term mean groundwater.

\subsection{Soil moisture response to subsequent cyclonic events}


In the northern part of Western Australia, the $\delta^{18} \mathrm{O}$ of groundwater is linked to the negative $\delta^{18} \mathrm{O}$ signatures of the largest volume cyclonic rainfall events (Skrzypek et al., 2013) occurring during the Austral summer while winters are dry with negligible precipitation (Rouillard et al., 2015). By contrast, the groundwater recharge in cold climates is often cold-season biased (Jasechko et al., 2017), because precipitation primarily occurs during cold seasons or is accumulated in the form of snow and ice and contributes to a delayed recharge during spring thawing. Hence, in cold climates, the $\delta^{18} \mathrm{O}$ value of groundwater reflects the winter precipitation and has a strong temperature effect (Rozanski et al., 1993). By contrast, the very negative values of $\delta^{18} \mathrm{O}$ for the rainfall from tropical cyclones in northwest Australia are associated with a rainout effect (Skrzypek et al., 2013). Nevertheless, in both cases, the groundwater stable isotope signature predominantly reflects the signature of the largest volume of precipitation.

The vertical distribution of the soil moisture content and the soil moisture stable oxygen isotope composition can be used as proxies for the assessment of the progress of evaporation and the depth of water infiltration (Or et al., 2012; Soderberg et al., 2011). Both parameters can be significantly modified by large-volume rainfall events and extended periods of drought (Benettin et al., 2018; Koeniger et al., 2016). The depth of infiltration and the extent of potential groundwater recharge may depend on multiple factors, such as the volumes, frequency of rainfall, soil properties and initial soil moisture content (Xu et al., 2019). Similarly, the progress of evaporation depends on the soil texture, mineralogy and tension (Gaj et al., 2016; 2017, 2019) The stable isotope fractionation in the soil profile may also depend on soil chemical and physical properties (Gaj et al., 2017). However, in the studied case the organic contents (Chen et al., 2016) influence on fractionation is negligible due to extremely low concentrations $<1 \%$ of carbon (Rouillard et al., 2016). Also, silica influence (Lin and Horita, 2016; Lin et al., 2017) at this location was rather negligible as the content of silicates were very low in dolocrate 
dominated environment (Mather et al., 2019). Potential secondary stable fractionations could be eventually associated with interactions with phyllosilicate clay minerals (Oerter et al., 2014) but the possible extent is unknown.

In arid and semiarid climates, small rainfall events (e.g. $<20 \mathrm{~mm}$ ) have no long-term implications for soil moisture or groundwater recharge and therefore winter precipitation has a negligible influence on water budget (Dogramaci et al., 2012; Harrington et al., 2002). During this study, we did not observe any changes in the soil moisture at a depth of $95 \mathrm{~cm}$ (determined at the Koodaideri Weather station using permanently installed soil moisture probes), even after $30 \mathrm{~mm}$ of daily rainfall events, provided that the events were separated by periods of drought (Fig. S5).

609

\subsubsection{Wet and drying of soil profiles visualised using "Polygon method"}

Similar to these differences registered by the data loggers, differences in the soil moisture contents and its $\delta^{18} \mathrm{O}$ signatures were also detected in the drilled soil cores with respect to the depth of cyclonic floodwater infiltration carrying unique negative $\delta^{18} \mathrm{O}$ signature. In order to visualise subsequent wetting and drying events, we proposed "a polygon method". First, we plotted $\delta^{18} \mathrm{O}$ in relation to the depth of soil moisture sample at one of the sampling location drilled four times before (red, blue, green and purple lines), between and after two major cyclones (Fig. 8). Second, we added to the plot recorded signatures of infiltrating precipitation 618 (black vertical dashed lines). Third, based on the $\delta^{18} \mathrm{O}$ vertical distribution we detected at what depth the unique $\delta^{18} \mathrm{O}$ signatures of the cyclones is observed. Fourth, we prepared a series of polygons reflecting the progress of evaporation between infiltration and sampling time comparing $\delta^{18} \mathrm{O}$ signatures of infiltrating water (X1, X2, X4, and X5). Plot X3 reflects mixing. 

completely replaced the soil moisture down to $\sim 3.5 \mathrm{~m}$ and at this depth signature of $-17.6 \%$

624

625

626

627

628

629

630

631

632

633

634

635

636

637

638

639

640

641

642

643

644

645

646

identical with mean TC Heidi precipitation was detected. The good agreement between dexcess of the soil moisture at $3.5 \mathrm{~m}$ (17.7) and precipitation (mean 15.6, initial 16.8) additionally confirms a rapid infiltration of unevaporated precipitation replacing residual moisture in the soil. At the same time, the soil moisture increased in the whole depth profile from 16.2 to $29.7 \%$. The depth of the floodwater infiltration could have been greater than 3.5 $\mathrm{m}$, but the $\delta^{18} \mathrm{O}$ signatures below this depth were more positive and therefore were likely to represent mixing between the floodwater and residual moisture retained in the soil from previous events. In the upper section of the core $>3.5 \mathrm{~m}$, the deviation in the $\delta^{18} \mathrm{O}$ from the initial value of the cyclone-related rainfall (-17.6\%) reflected the progress of evaporation from the soil profile over the period of 41 days between the cyclone and the subsequent sampling. The magnitude of the evaporative loss is reflected in the size of the polygon X1 (Fig. 8), calculated as a triangular area between the vertical line marking the signature of the cyclone ($17.6 \%$ o, the horizontal line at the shallowest sampling point $(0.4 \mathrm{~m})$ and the regression line for the upper part of the core (filled points).

In contrast to the rainfall from TC Heidi $(213 \mathrm{~mm})$, the lower rainfall from TC Lua (33 $\mathrm{mm})$, occurring six weeks later, replaced the soil moisture down to lower depth $(\sim 2 \mathrm{~m})$ and contributed to soil moisture down to $\sim 3 \mathrm{~m}$; at $\sim 2.5 \mathrm{~m}$ bgl, the contributions from TC Lua and TC Heidi were about 50:50 (Fig. 8, middle of the polygon X3). These differences reflect both the volume of rainfall and the soil conditions, as TC Lua occurred when the soil was still relatively wet from TC Heidi. Polygon X2 (Fig. 8) reflects the progressive evaporation that occurred between TC Lua and the subsequent sampling on 17 May 2012. The slope B of the regression line (-0.50, top nine filled points), which describes the change in $\delta^{18} \mathrm{O}$ with depth, was fit to points at the depth of $\geq 2 \mathrm{~m}$ and was consistent with the slope observed for the previous 
sampling after TC Heidi (slope B -0.45 , fitted to points $>3.5 \mathrm{~m}$, filled blue points). The soil $\delta^{18} \mathrm{O}$ values consistently increased between $\sim 2 \mathrm{~m}$ and $\sim 3 \mathrm{~m}$, reflecting the expected mixing between the soil moisture retained in the profile from TC Heidi and the water infiltrating from TC Lua. Below $3 \mathrm{~m}$, the soil $\delta^{18} \mathrm{O}$ decreased again, primarily reflecting the signature of partially evaporated soil moisture from TC Heidi. The regression line fitted to the soil data below $3 \mathrm{~m}$ had a slope of -0.31 (green dashed line based on five open points, Fig. 8). The $\delta^{18} \mathrm{O}$ of soil water from TC Heidi would have been expected to fall along this line if TC Lua had not occurred (e.g., at 2 m, -5 \%o would be expected, rather than -11.6 \%). The polygon X3 (green line X3, Fig. 8), enveloped by the dashed vertical line for the signature of TC Lua (-11.6 \%o) and the regression line with the slope $C(-0.31)$, reflects the relative contribution to soil moisture at different depths from the two cyclones, Heidi and Lua. The polygon X4 in the deeper section of the soil, enveloped by the signatures from TC Heidi (blue line) and TC Lua (green line), reflects the direct evaporative losses occurring over the three-month interval between 23/02/2012 and 17/05/2012 and is considered as not impacted by infiltration from Lua. The stable isotope composition of the top part of the soil profile (upper $\sim 2 \mathrm{~m}$ ) had almost returned to the values observed prior to Heidi after 21 months (sampling 12 November 2013). The size of polygon X5 reflects the evaporative loss from the soil profile between the previous sampling after TC Lua (17/05/2012) and the final sampling (7/11/2013) (Fig. 8), however this polygon is just a conceptual approximation, as others not sampled small precipitation events occurred in the meantime (Fig. S1).

667

\subsubsection{Quantification of evaporative loses using "Isothermal evaporation model”}

The polygon method allows good visualisation of the significance of the major soil moisture budget drivers but applying the classical model proposed by Allison et al. (1983, 1988), as per Equations 1-3, the actual evaporative losses before and after both events can be 
672

673

674

675

676

677

678

679

680

681

682

683

684

685

686

687

688

689

690

691

692

693

694

695

estimated. By contrast, the evaporative loss from soil was much lower after an extended dry period, and it likely reflected a nearly steady-state condition, as it did not exceed $30 \mathrm{~mm} \mathrm{y}^{-1}$ across the drilling transect. All the $\delta^{18} \mathrm{O}$ in the soil can be seen as transient, but the cyclone $\delta^{18} \mathrm{O}$ reflects the original $\delta^{18} \mathrm{O}$ of the initial water undergoing evaporation in the upper part of the soil profile. Therefore, cyclone water, rather than groundwater, should be used for $\delta_{\text {res }}$ (Eq. 1-3). In addition, active diffusivity at the deeper part of the soil profiles will be negligible due to the nearly saturated conditions that restrict diffusion from the groundwater table, but reequilibration in the liquid phase can still occur despite the absence of diffusion. The evaporative loss from the soil profile wetted by TC Heidi, as observed at the time of sampling on 23/02/2012, was between 0.21 and $0.32 \mathrm{~mm} \times \mathrm{day}^{-1}$ (with respect to the assumed active diffusivity between 2.0 and $2.310^{-9} \mathrm{~m}^{2} \times \mathrm{s}^{-1}$ ), which equals between $\sim 77$ and $\sim 118 \mathrm{~mm} \times \mathrm{yr}^{-1}$. These momentary values are approximately two to four times higher than those seen during dry conditions. By contrast, the evaporative loss from the soil profile after TC Lua, as recorded on 17/05/2012, was much higher and varied between 0.38 and $0.60 \mathrm{~mm} \times \mathrm{day}^{-1}$ (140 and 220 $\left.\mathrm{mm} \times \mathrm{yr}^{-1}\right)$. The evaporation from the soil depends not only on the soil properties and climatic parameters but primarily on the presence of moisture in the soil and its vertical distribution. Nevertheless, the highest average annual recharge $\left(6.1 \mathrm{~mm} \times \mathrm{yr}^{-1}\right)$ estimated for the study location is 1.3 to 4.9 times lower than the momentary evaporation after the extended dry period (8-30 mm× $\times \mathrm{yr}^{-1}$ ). This discrepancy will be a magnitude higher when compared to the extremely high evaporation from wet soil observed in the central part of the study site over the weeks directly following cyclone events.

\section{Conclusions}



a unique hydrological tracer that is distributed on a regional scale over a landmass and that can

698 be successfully applied to study evaporative losses and moisture replenishment in soil profiles and groundwater recharge. We show that the soil moisture $\delta^{18} \mathrm{O}$ value varies within the top $\sim 4$ $\mathrm{m}$ of soil profiles with respect to the time since the most recent large rainfall event. Thus, the $\delta^{18} \mathrm{O}$ of soil moisture reflects the progress of evaporation as well as the mixing that occurs between the residual soil moisture and the infiltration from previous rainfall events. In parallel, the groundwater $\delta^{18} \mathrm{O}$ primarily reflects the weighted-by-volume mean of infrequent but largevolume recharge events. This $\delta^{18} \mathrm{O}$ signature of the recharge water persists in the soil moisture during infiltration only for several weeks following the recharge event. All the observed differences in the $\delta^{18} \mathrm{O}$ values between rainfall, soil moisture and groundwater can be explained by differences in the evaporation rates during different time intervals and the subsequent mixing with infiltrating water from subsequent rainfalls. Our study shows that large spatial variability exists on the scale from meters to hundreds of meters and that the position in the landscape plays a critical role in retention and replenishment of soil water; this needs to be considered while upscaling local data to global models.

\section{Acknowledgments}

This research was primarily funded by Rio Tinto (RTIO), and further supported by the Australian Research Council (ARC) in partnership with Rio Tinto (LP120100310) and an ARC Future Fellowship awarded to G. Skrzypek (FT110100352). We are grateful to our teams at RTIO and The University of Western Australia (UWA) whose contributions made this study possible. In particular, we thank Jay Matta, Wade Dodson, Tim Eckersley and Sally Madden who organised and supervised the sonic drilling; Kate Bailue, Paul Hedley and Krista 
Sanderson, who collected rainwater and bore samples; Samuel Lucitti who assisted with soil sampling and collection of floodwater samples; Andre Siebers for the assistance in the field and Douglas Ford, Kate Bowler and Ela Skrzypek at the West Australian Biogeochemistry Centre at UWA who helped with stable isotope analyses.

\section{References}

Abdalla, O., Al-Abri, R.Y., 2011. Groundwater recharge in arid areas induced by tropical cyclones: Lessons learned from Gonu 2007 in Sultanate of Oman. Environmental Earth Sciences 63, 229-239.

Allison, G.B., Barnes, C.J., 1985. Estimation of evaporation from the normally "dry" Lake Frome in South Australia. Journal of Hydrology 78, 229-242.

Allison, G.B., Barnes, C.J., Hughes, M.W., 1983. The distribution of deuterium and 180 in dry soils 2. Experimental. Journal of Hydrology 64, 377-397.

Allison, G.B., Barnes, C.J., Hughes, M.W., Leaney, F.W.J., 1984. Effect of climate and vegetation on oxygen-18 and deuterium profiles in soils. Isotope hydrology 1983. Proc. symposium, Vienna, (IAEA; STI/PUB/650), pp. 105-123.

Bakhtiari, B., Ghahraman, N., Liaghat, A.M. and Hoogenboom, G., 2010. Evaluation of reference evapotranspiration models for a semiarid environment using lysimeter measurements. Journal of Agricultural Science and Technology 13, 223-237.

Barnes, C.J., Allison, G.B., 1988. Tracing of water movement in the unsaturated zone using stable isotopes of hydrogen and oxygen. Journal of Hydrology 100, 143-176.

Benettin, P., Volkmann, T.H.M., Von Freyberg, J., Frentress, J., Penna, D., Dawson, T.E., Kirchner, J.W., 2018. Effects of climatic seasonality on the isotopic composition of evaporating soil waters. Hydrology and Earth System Sciences 22, 2881-2890.

Bowman, D.M.J.S., Brown, G.K., Braby, M.F., Brown, J.R., Cook, L.G., Crisp, M.D., Ford, F., Haberle, S., Hughes, J., Isagi, Y., Joseph, L., McBride, J., Nelson, G., Ladiges, P.Y., 2010. Biogeography of the Australian monsoon tropics. Journal of Biogeography 37, 201-216.

Cane, G., Clark, I.D., 1999. Tracing Ground Water Recharge in an Agricultural Watershed with Isotopes. Groundwater 37, 133-139.

Chen, G., Auerswald, K., Schnyder, H., 2016. ${ }^{2} \mathrm{H}$ and ${ }^{18} \mathrm{O}$ depletion of water close to organic surfaces. Biogeosciences 13, 3175-3186.

Clark, I.D., Fritz, P., 1997. Environmental Isotopes in Hydrogeology. Lewis Publishers, p. 352 ISBN: 1-56670-249-6.

Coenders-Gerrits, A.M.J., van der Ent, R.J., Bogaard, T.A., Wang-Erlandsson, L., Hrachowitz, M., Savenije, H.H.G. 2014. Uncertainties in transpiration estimates. Nature 506, E1E2.

Cook, P.G., O'Grady, A.P., 2006. Determining soil and ground water use of vegetation from heat pulse, water potential and stable isotope data. Oecologia 148, 97-107.

Coplen, T.B., 1996. New guidelines for reporting stable hydrogen, carbon, and oxygen isotoperatio data. Geochimica et Cosmochimica Acta. 60, 3359.

Craig, H., Gordon, L.I., 1965. Deuterium and oxygen 18 variations in the ocean and the marine atmosphere. In: Ongiorgi, E. (Ed.), Stable Isotopes in Oceanographic Studies and Paleotemperatures. Laboratorio di Geologia Nucleare, Pisa, pp. 9-130. 
Crosbie R.S., Peeters L.J.M., Herron N., McVicar T.R., Herr A., 2017. Estimating groundwater recharge and its associated uncertainty: Use of regression kriging and the chloride mass balance method. Journal of Hydrology 561, 1063-1080.

Dansgaard, W., 1964. Stable isotopes in precipitation, Tellus 16, 436-438.

Dijkema, J., Koonce, J.E., Shillito, R.M., Ghezzehei, T.A., Berli, M., van der Ploeg, M.J. and van Genuchten, M.T., 2017. Water Distribution in an Arid Zone Soil: Numerical Analysis of Data from a Large Weighing Lysimeter. Vadose Zone Journal.

Dodorico, P., Carr, J., Laio, F., Ridolfi, L., 2012. Spatial organization and drivers of the virtual water trade: A community-structure analysis. Environmental Research Letters 7, 034007.

Dogramaci S., Firmani G., Hedley P., Skrzypek G., Grierson P.F., 2015. Evaluating recharge to an ephemeral dryland stream using a hydraulic model and water, chloride and isotope mass balance. Journal of Hydrology 521, 520-532.

Dogramaci S., McLean L., Skrzypek G., 2017. Hydrochemical and stable isotope indicators of pyrite oxidation in carbonate-rich environment; the Hamersley Basin, Western Australia. Journal of Hydrology 545, 288-298.

Dogramaci S., Skrzypek G., Dodson W., Grierson P.F., 2012, Stable isotope and hydrochemical evolution of groundwater in the semi-arid Hamersley Basin of subtropical northwest Australia. Journal of Hydrology 475, 281-293.

Dubbert, M., Cuntz, M., Piayda, A., Maguás, C., Werner, C., 2013. Partitioning evapotranspiration - Testing the Craig and Gordon model with field measurements of oxygen isotope ratios of evaporative fluxes. Journal of Hydrology 496, 142-153.

Eastoe, C.J., Hess, G., Mahieux, S., 2015. Identifying Recharge from Tropical Cyclonic Storms, Baja California Sur, Mexico. Groundwater, 53, 133-138.

Evaristo, J., Jasechko, S., McDonnell, J.J., 2015. Global separation of plant transpiration from groundwater and streamflow. Nature 525, 91-94.

Fellman J., Dogramaci S, Skrzypek G., Dodson W, Grierson P., 2011. Hydrologic control of dissolved organic matter biogeochemistry in pools of a subtropical dryland river, Western Australia. Water Resources Research 47, W06501.

Gaj, M., Beyer, M., Koeniger, P., Wanke, H., Hamutoko, J., Himmelsbach, T., 2016. In situ unsaturated zone water stable isotope $\left({ }^{2} \mathrm{H}\right.$ and $\left.{ }^{18} \mathrm{O}\right)$ measurements in semi-arid environments: a soil water balance. Hydrology and Earth System Sciences 20, 715-731.

Gaj, M., Kaufhold, S., Koeniger, P., Beyer, M., Weiler, M. and Himmelsbach, T., 2017. Mineral mediated isotope fractionation of soil water. Rapid Communications in Mass Spectrometry 31, 269-280.

Gaj, M., Lamparter, A., Woche, S.K., Bachmann, J., McDonnell, J.J., Stange, C.F., 2019. The role of matric potential, solid interfacial chemistry, and wettability on isotopic equilibrium fractionation. Vadose Zone J. 18:180083.

Gat, J.R., 1995. Stable isotopes of fresh and saline lakes. In: Lerman, D.I. (Ed.), Physics and Chemistry of Lakes. Springer, pp. 139-165.

Gat, J.R., 2010. Isotope Hydrology. Imperial College Press. Series on Environmental Science and Management vol. 6, p. 189.

Gedzelman, S.D., Lawrence, J.R., 1982. The isotopic composition of cyclonic precipitation (Palisades, NY). Journal of Applied Meteorology 21, 1385-1404.

Gedzelman, S.D., Lawrence, J.R., 1990. The isotopic composition of precipitation from two extratropical cyclones. Monthly Weather Review 118, 495-509.

Gibson, J.J., Reid, R., 2014. Water balance a chain of tundra lakes: a 20-years isotopic perspective. J. Hydrol. 519, 2148-2164. 
Good, S.P., Mallia, D.V., Lin, J.C., Bowen, G.J., 2014. Stable Isotope Analysis of Precipitation Samples Obtained via Crowdsourcing Reveals the Spatiotemporal Evolution of Superstorm Sandy. PLoS ONE 9(3): e91117.

Guan H., Zhang X., Skrzypek G., Sun Z., 2013. Deuterium excess variations of rainfall events in a coastal area of South Australia and its relationship with synoptic weather patterns and atmospheric moisture sources. Journal of Geophysical Research: Atmospheres 118, 1123-1138.

Harrington, G.A., Cook, P.G., Herczeg, A.L., 2002. Spatial and temporal variability of groundwater recharge in central Australia: a tracer approach. Ground Water 40, 518528.

Hasselquist, N. J., Benegas, L., Roupsard, O., Malmer, A., Ilstedt, U., 2018. Canopy cover effects on local soil water dynamics in a tropical agroforestry system: Evaporation drives soil water isotopic enrichment. Hydrological Processes 32, 994-1004.

Haverd, V., Cuntz, M., 2010. Soil-Litter-Iso: A one-dimensional model for coupled transport of heat, water and stable isotopes in soil with a litter layer and root extraction. Journal of Hydrology 388, 438-455.

Hendry, M.J., Schmeling, E., Wassenaar, L.I., Barbour, S.L., Pratt, D., 2015. Determining the stable isotope composition of pore water from saturated and unsaturated zone core: improvements to the direct vapour equilibration laser spectrometry method, Hydrol. Earth Syst. Sci. 19, 4427-4440.

Herczeg, A.L., Leaney, F.W., 2011. Review: Environmental tracers in arid-zone hydrology Hydrogeology Journal 19, 17-29.

Hollins, S.E., Hughes, C.E., Crawford, J., Cendón, D.I., Meredith, K.M., 2018. Rainfall isotope variations over the Australian continent-Implications for hydrology and isoscape applications. Science of the Total Environment 645, 630-645.

Horita, J., Rozanski, K., Cohen, S., 2008. Isotope effects in the evaporation of water: a status report of the Craig-Gordon model. Isot. Environ. Health Stud. 44, 23-49.

Huxman, T.E., Snyder, K.A., Tissue, D., Leffler, A.J., Ogle, K., Pockman, W.T., Sandquist, D.R., Potts, D.L., Schwinning, S. 2004. Precipitation pulses and carbon fluxes in semiarid and arid ecosystems. Oecologia 141, 254-268

Jasechko, S., Sharp, Z.D., Gibson, J.J., Birks, S.J., Yi, Y., Fawcett, P.J., 2013. Terrestrial water fluxes dominated by transpiration. Nature 496, 347-350.

Jasechko, S., Wassenaar, L.I., Mayer. B., 2017. Isotopic evidence for widespread cold-seasonbiased groundwater recharge and young streamflow across central Canada. Hydrological Processes31, 2196-2209.

Jones, D.A., 2009, High-quality spatial climate data-sets for Australia. Australian Meteorological and Oceanographic Journal 58, 233-248.

Kam, J., Sheffield, J., Yuan, X., Wood, F.E., 2013. The influence of Atlantic tropical cyclones on drought over the Eastern United States (1980-2007). Journal of Climate, 26, 30673086.

Khouakhi, A., Villarini, G., Vecchi, G.A., 2017. Contribution of tropical cyclones to rainfall at the global scale. Journal of Climate, 30, 359-372.

Koeniger, P., Gaj, M., Beyer, M., Himmelsbach, T., 2016. Review on soil water isotope-based groundwater recharge estimations. Hydrological Processes 30, 2817-2834.

Lavender, S.L., Abbs, D.J., 2013. Trends in Australian rainfall: Contribution of tropical cyclones and closed lows. Climate Dynamics 40, 317-326.

Lawrence, J.R., Gedzelman, S.D., Zhang, X., Arnold, R., 1998. Stable isotope ratios of rain and vapor in 1995 hurricanes. Journal of Geophysical Research Atmospheres 103, 11381-11400. 
Lawrence, J.R., Gedzelman, S.D.Low stable isotope ratios of tropical cyclone rains (1996) Geophysical Research Letters 23, 527-530.

Lin, Y., Horita, J., 2016. An experimental study on isotope fractionation in a mesoporous silicawater system with implications for vadose-zone hydrology. Geochimica et Cosmochimica Acta 184, 257-271.

Lin, Y., Horita, J., Abe, O., 2017. Adsorption isotope effects of water on mesoporous silica and alumina with implications for the land-vegetation-atmosphere system. Geochimica et Cosmochimica Acta. 223, 520-536.

Mather C.C., Nash DJ, Dogramaci S, Grierson PF, Skrzypek G., 2019. Geomorphic and hydrological controls on groundwater dolocrete formation in the semi-arid Hamersley Basin, northwest Australia. Earth Surface Processes and Landforms (in press).

McFarlane, D, 2015, Water resource assessment for the Pilbara. Australia: CSIRO. csiro:EP157751. https://doi.org/10.4225/08/584af1d54c68f

Meredith, K.T., Han, L.F., Cendón, D.I., Crawford, J., Hankin, S., Peterson, M., Hollins, S.E., 2018. Evolution of dissolved inorganic carbon in groundwater recharged by cyclones and groundwater age estimations using the ${ }^{14} \mathrm{C}$ statistical approach. Geochimica et Cosmochimica Acta 220, 483-498.

Mills, R., 1973. Self-diffusion in normal and heavy water in the range 1-45.deg. J. Phys. Chem., 77, 685-688.

Mook, W.G., Bommerson, J.C., Staverman, W.H., 1974. Carbon isotope fractionation between dissolved bicarbonate and gaseous carbon dioxide. Earth and Planetary Science Letters 22, 169-176.

Müller, T., Osenbrück, K., Strauch, G., Pavetich, S., Al-Mashaikhi, K.-S., Herb, C., Merchel, S., Rugel, G., Aeschbach, W., Sanford, W., 2016. Use of multiple age tracers to estimate groundwater residence times and long-term recharge rates in arid southern Oman. Applied Geochemistry 74, 67-83.

Munksgaard, N.C., Zwart, C., Kurita, N., Bass, A., Nott, J., Bird, M.I., 2015. Stable Isotope Anatomy of Tropical Cyclone Ita, North-Eastern Australia. PLoS ONE 10(3): e0119728.

Nicholson, S.E., 2000. The nature of rainfall variability over Africa on time scales of decades to millennia. Global and Planetary Change 26, 137-158.

Oerter, E. J., Bowen, G., 2017. In situ monitoring of $\mathrm{H}$ and $\mathrm{O}$ stable isotopes in soil water reveals ecohydrologic dynamics in managed soil systems. Ecohydrology 10, e1841.

Oerter, E., Finstad, K., Schaefer, J., Goldsmith, G.R., Dawson, T., Amundson, R., 2014. Oxygen isotope fractionation effects in soil water via interaction with cations (Mg, Ca, $\mathrm{K}, \mathrm{Na}$ ) adsorbed to phyllosilicate clay minerals. Journal of Hydrology 515, 1-9.

Oki, T., Kanae, S., 2006. Global Hydrological Cycles and World Water Resources. Science 313, 1068-1072.

Or, D., Lehmann, P., Shahraeeni, E., Shokri, N., 2013. Advances in soil evaporation physicsA review. Vadose Zone Journal 12 (4).

Rossi, M.J., Ares, J.O., Jobbágy, E.G., Vivoni, E.R., Vervoort, R.W., Schreiner-McGraw, A.P., Saco, P.M., 2018. Vegetation and terrain drivers of infiltration depth along a semiarid hillslope. Science of the Total Environment 644, 1399-1408.

Rouillard A., Greenwood P., Grice K., Skrzypek G., Dogramaci S., Turney C., Grierson P.F., 2016. Interpreting vegetation change in tropical arid ecosystems from sediment molecular fossils and their stable isotope compositions: A baseline study from the Pilbara region of northwest Australia. Palaeogeography, Palaeoclimatology, Palaeoecology 459, 495-507. 
Rouillard, A., Skrzypek, G., Dogramaci, S., Turney, C., Grierson, P.F., 2015. Impacts of high inter-annual variability of rainfall on a century of extreme hydrological regime of northwest Australia. Hydrology and Earth System Sciences 19, 2057-2078.

Rozanski, K., Araguas-Araguas, L., and Gonfiantini, R., 1993. Isotopic patterns in modern global precipitation, in Swart, P.K., et al., eds., Climate change in continental isotopic records: American Geophysical Union Geophysical Monograph 78, p. 1-36.

Scanlon, B.R., Keese, K.E., Flint, A.L., Flint, L.E., Gaye, C.B., Edmunds, W.M., Simmers, I., 20006. Global synthesis of groundwater recharge in semiarid and arid regions. Hydrological Processes 20, 3335-3370.

Schlesinger, W.H., Jasechko, S., 2014. Transpiration in the global water cycle. Agricultural and Forest Meteorology 189-190, 115-117.

Shi, G., Cai, W., Cowan, T., Ribbe, J., Rotstayn, L., Dix, M., 2008. Variability and trend of North West Australia rainfall: observations and coupled climate modeling. J. Clim. 21, 2938-2959.

Skrzypek, G., Dogramaci, S., Grierson, P.F., 2013. Geochemical and hydrological processes controlling groundwater salinity of a large inland wetland of northwest Australia. Chemical Geology 357, 164-177.

Skrzypek, G., Dogramaci, S., Grierson, P.F., 2013. Geochemical and hydrological processes controlling groundwater salinity of a large inland wetland of northwest Australia. Chemical Geology 357, 164-177.

Skrzypek, G., Dogramaci, S., Rouillard, A., Grierson, P.E., 2016. Groundwater seepage controls salinity in a hydrologically terminal basin of semi-arid northwest Australia. Journal of Hydrology 542, 627-636.

Skrzypek, G., Ford, D., 2014. Stable isotope analyses of saline water samples on a cavity ringdown spectroscopy instrument. Environmental Science \& Technology 48, 2827-2834.

Soderberg, K., Good, S.P., Wang, L., Caylor, K., 2012. Stable isotopes of water vapor in the vadose zone: A review of measurement and modeling techniques. Vadose Zone Journal 11 (3).

Sprenger, M., Tetzlaff, D., Soulsby, C., 2017. Soil water stable isotopes reveal evaporation dynamics at the soil-plant-atmosphere interface of the critical zone. Hydrology and Earth System Sciences 21, 3839-3856.

Stumpp, C., Maloszewski, P., 2010. Quantification of preferential flow and flow heterogeneities in an unsaturated soil planted with different crops using the environmental isotope $\delta^{18} \mathrm{O}$. Journal of Hydrology 394, 407-415.

Tollenaar, R.N., van Paassen, L.A., Jommi, C., 2017. Small-scale evaporation tests on clay: influence of drying rate on clayey soil layer. Canadian Geotechnical Journal 55, 437445.

Villarini, G., Denniston, R.F., 2016. Contribution of tropical cyclones to extreme rainfall in Australia. International Journal of Climatology 36, 1019-1025.

Walker, G.R., Hughes, M.W., Allison, G.B., Barnes, C.J., 1988. The movement of isotopes of water during evaporation from bare soil surface. Journal of Hydrology 97, 181-197.

Wallace J., Devereux D., 2013. Monitoring of Coolibah Woodlands on Mt Bruce Flats using Remote Sensing. CSIRO Consulting report for RTIO, RTIO-HSE-0193960.

Wang, L., Good, S.P., Caylor, K.K. 2014. Global synthesis of vegetation control on evapotranspiration partitioning. Geophysical Research Letters 41, 6753-6757.

Wassenaar, L.I., Hendry, M.J., Chostner, V.L., Lis, G.P., 2008. High Resolution Pore Water $\delta^{2} \mathrm{H}$ and $\delta^{18} \mathrm{O}$ Measurements by $\mathrm{H}_{2} \mathrm{O}$ (liquid) $-\mathrm{H}_{2} \mathrm{O}$ (vapor) Equilibration Laser Spectroscopy. Environ. Sci. Technol. 42, 9262-9267. 
Xu X., Guan H., Skrzypek G., Simmons C.T., 2018. Root-zone Moisture Replenishment in a Native Vegetated Catchment under Mediterranean Climate. Hydrological Processes (in press DOI:10.1002/hyp.13475)

Zwart, C., Munksgaard, N.C., Kurita, N., Bird, M.I., 2016. Stable isotopic signature of Australian monsoon controlled by regional convection. Quaternary Science Reviews 151, 228-235.

Zwart, C., Munksgaard, N.C., Protat, A., Kurita, N., Lambrinidis, D., Bird, M.I., 2018. The isotopic signature of monsoon conditions, cloud modes, and rainfall type. Hydrological Processes. 32, 2296- 2303. 


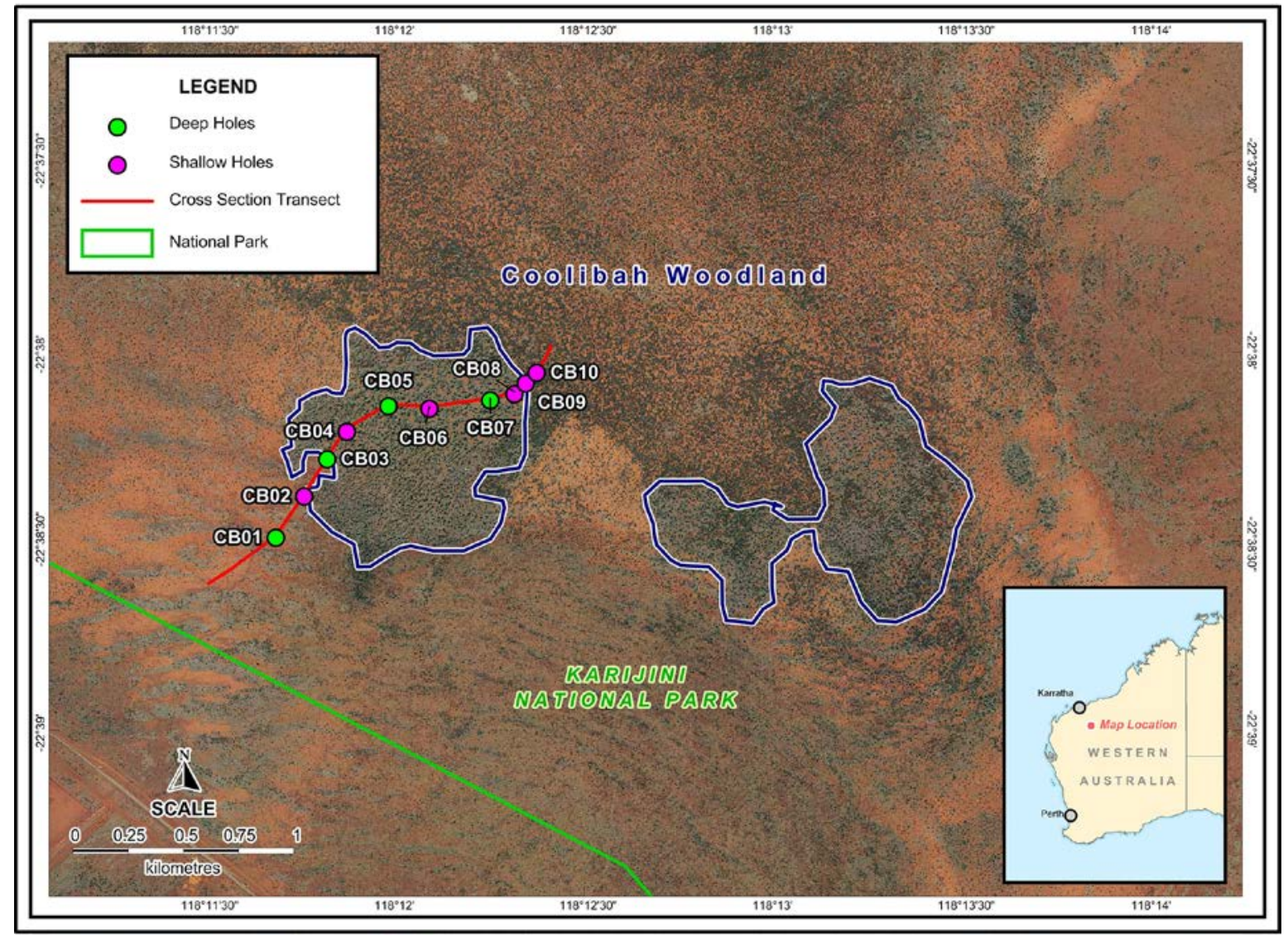

Figure 1. Location of the soil sampling transect in the Coolibah Woodlands (Fig. 5 and 6), Karijini National Park (705 m asl, 22³8' S, 118²12' E). The nearest rainwater sampling station at Marandoo is located about $10 \mathrm{~km}$ to the South East. The blue outlines embrace the Coolibah Woodland patches. 


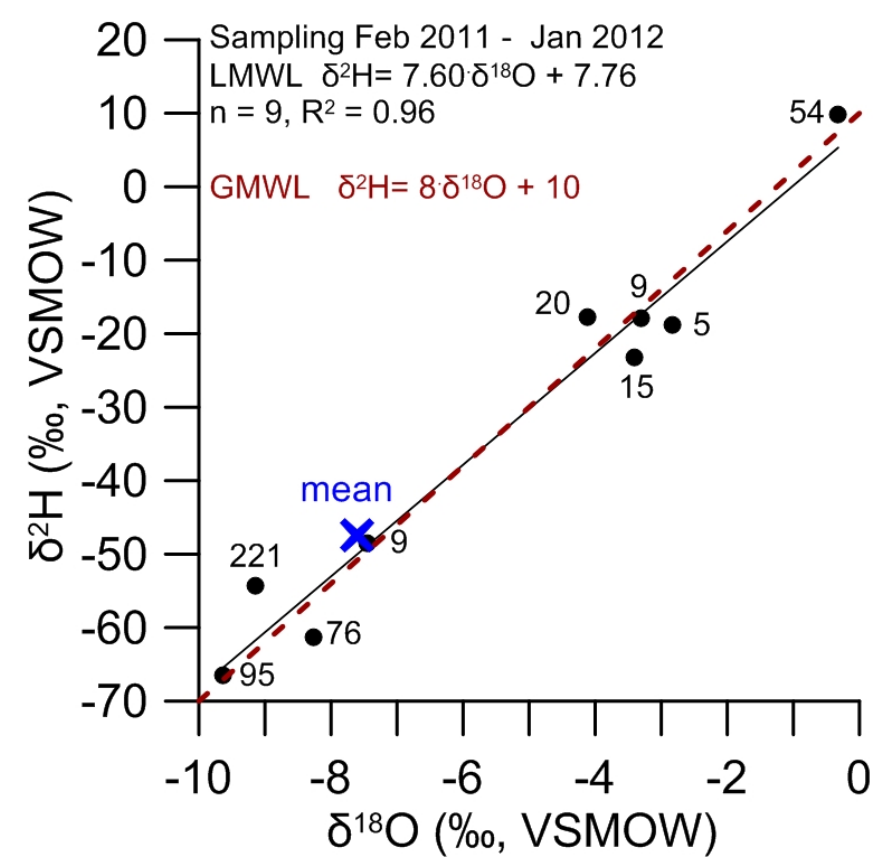

Figure 2. Local Meteoric Water Line (LMWL) for Hope Downs (660 m a.s.1., $23^{\circ} 8^{\prime} \mathrm{S}, 119^{\circ}$ $34^{\prime}$ E) based on monthly sampling over the 2011-2012 period. The labels indicate the total monthly precipitation ( $\mathrm{mm}$ ). The weighed by volume annual means (blue cross symbol) were $\delta^{18} \mathrm{O}-7.6 \%$ and $\delta^{2} \mathrm{H}-47.4 \%$. 

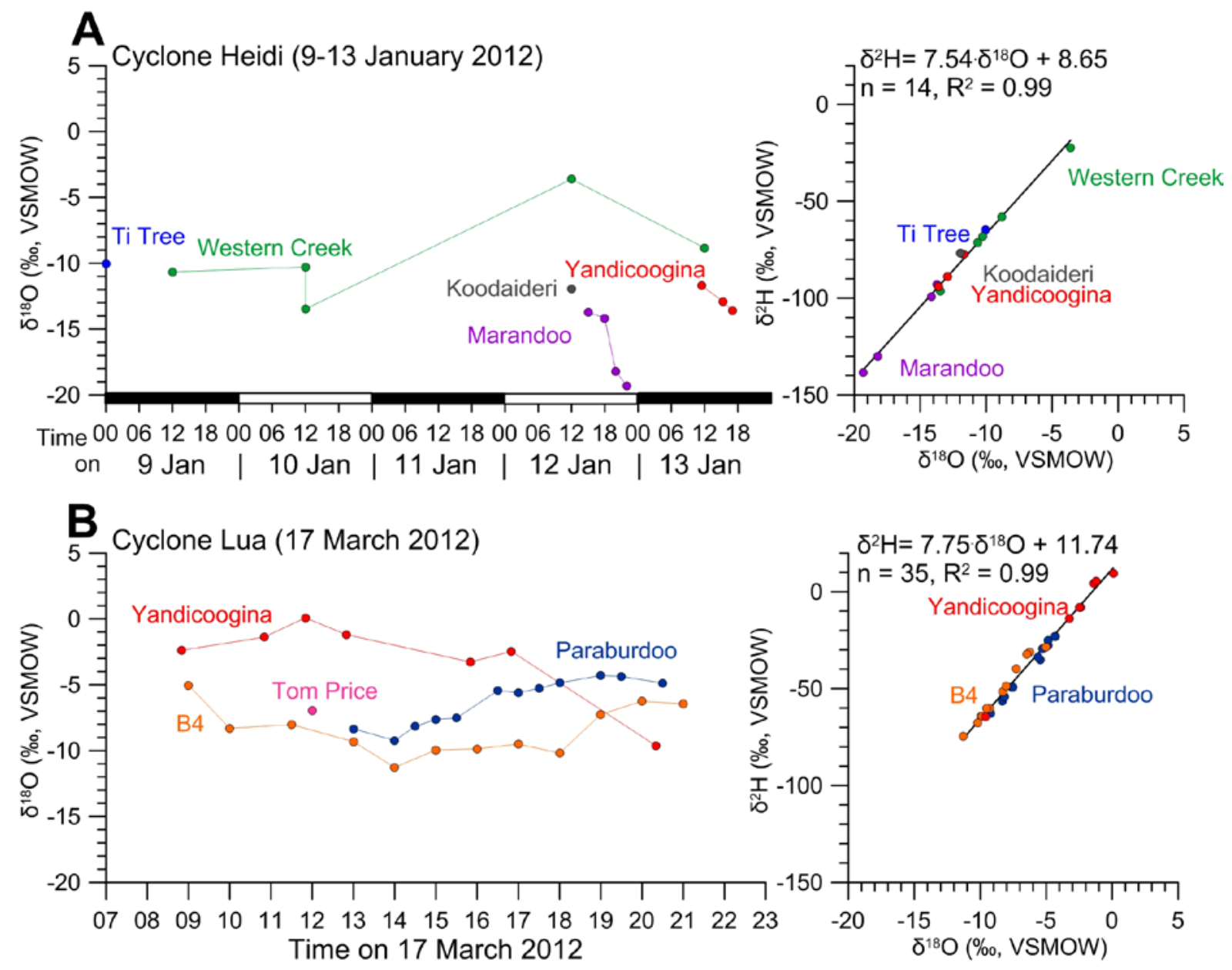

Figure 3. The stable isotope composition of precipitation collected at several locations across Pilbara during TC Heidi and TC Lua. The samples were collected continuously and $\delta^{18} \mathrm{O}$ plotted respectively to the time of the collection. Marandoo and B4 are the rainwater collection sites nearest to the soil-sampling site at the Coolibah Woodlands in the Karijini National Park. The regression equation for the $\delta^{2} \mathrm{H}-\delta^{18} \mathrm{O}$ relationship for each of the sites separately and each cyclone is not different from the LMWL obtained for Hope Downs (Fig. 2) and close to GWML $\delta^{2} \mathrm{H}=8 \delta^{18} \mathrm{O}+10$. 

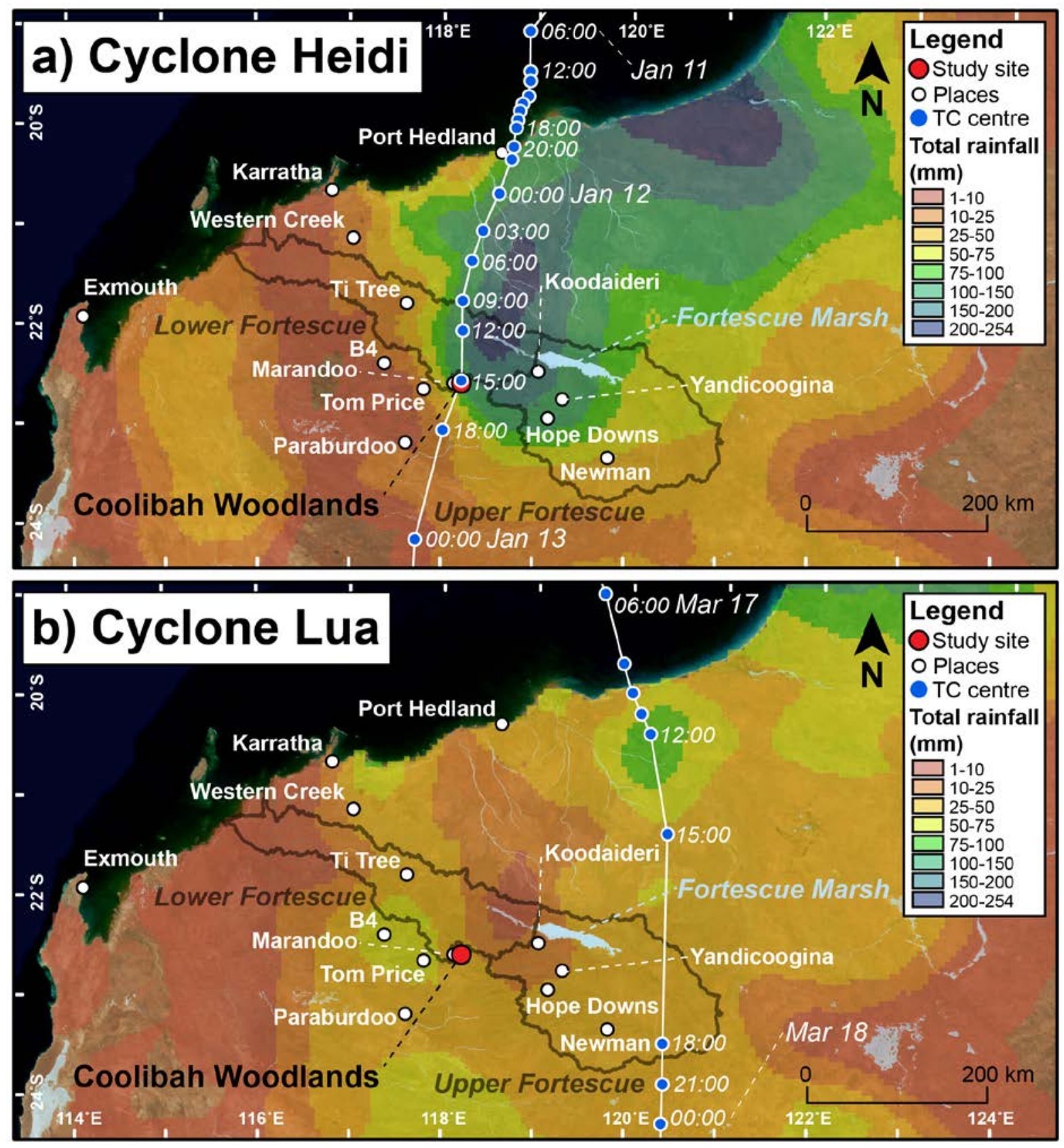

Figure 4. Total rainfall over NW Australia during the passage of TC Heidi (a) and TC Lua (b) on land in 2012 (compiled from $0.05^{\circ}$ gridded BoM daily rainfall datasets; Jones et al., 2019), including hourly tracks (blue circles) of the cyclone centre (unless specified); catchment delineation (black outline) of the Upper Fortescue $\left(29,800 \mathrm{~km}^{2}\right)$ and Lower Fortescue $(19,800$ $\left.\mathrm{km}^{2}\right)$; and the Fortescue Marsh at it's maximum extent $\left(1,200 \mathrm{~km}^{2}\right)$. 


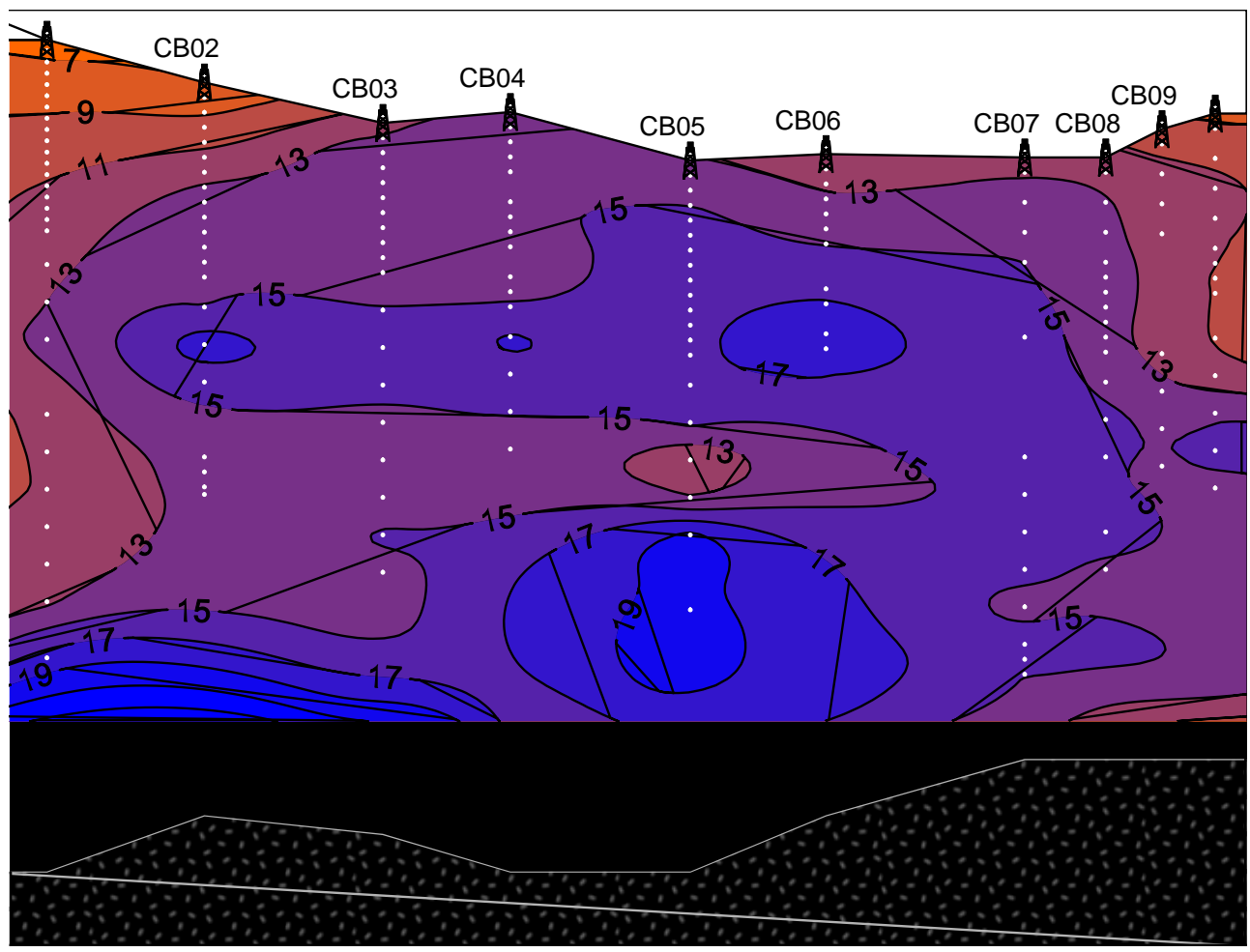

Figure 5. The baseline in dry conditions - soil water contents along the sampling transect in the Coolibah Woodlands in the Karijini National Park (Fig. 1). White dots represent soil-sampling depths. WT - water table. The interpolation range was restricted to the depth at $688 \mathrm{~m}$ asl. 


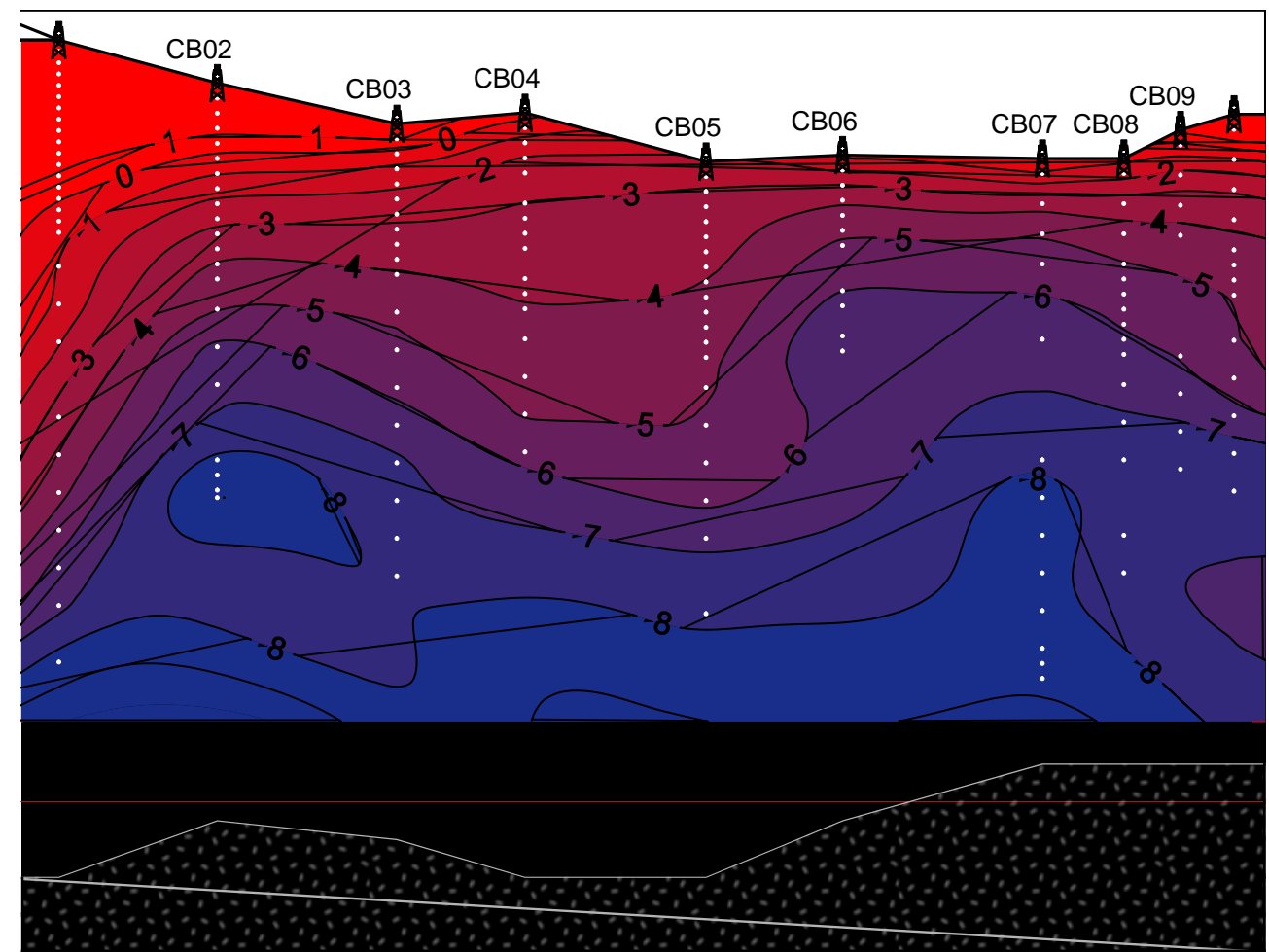

Figure 6. The baseline in dry conditions - soil water stable isotope composition along the sampling transect in the Coolibah Woodlands, the Karijini National Park (Fig. 1) on November 2010, white dots represent soil-sampling depths. WT - water table. Groundwater $\delta^{18} \mathrm{O}=$ $9.03 \pm 0.56 \%$ (on December 2012). The interpolation range was restricted to the depth at $688 \mathrm{~m}$ asl. (raw detailed data are presented in Fig. S2 and S4). 


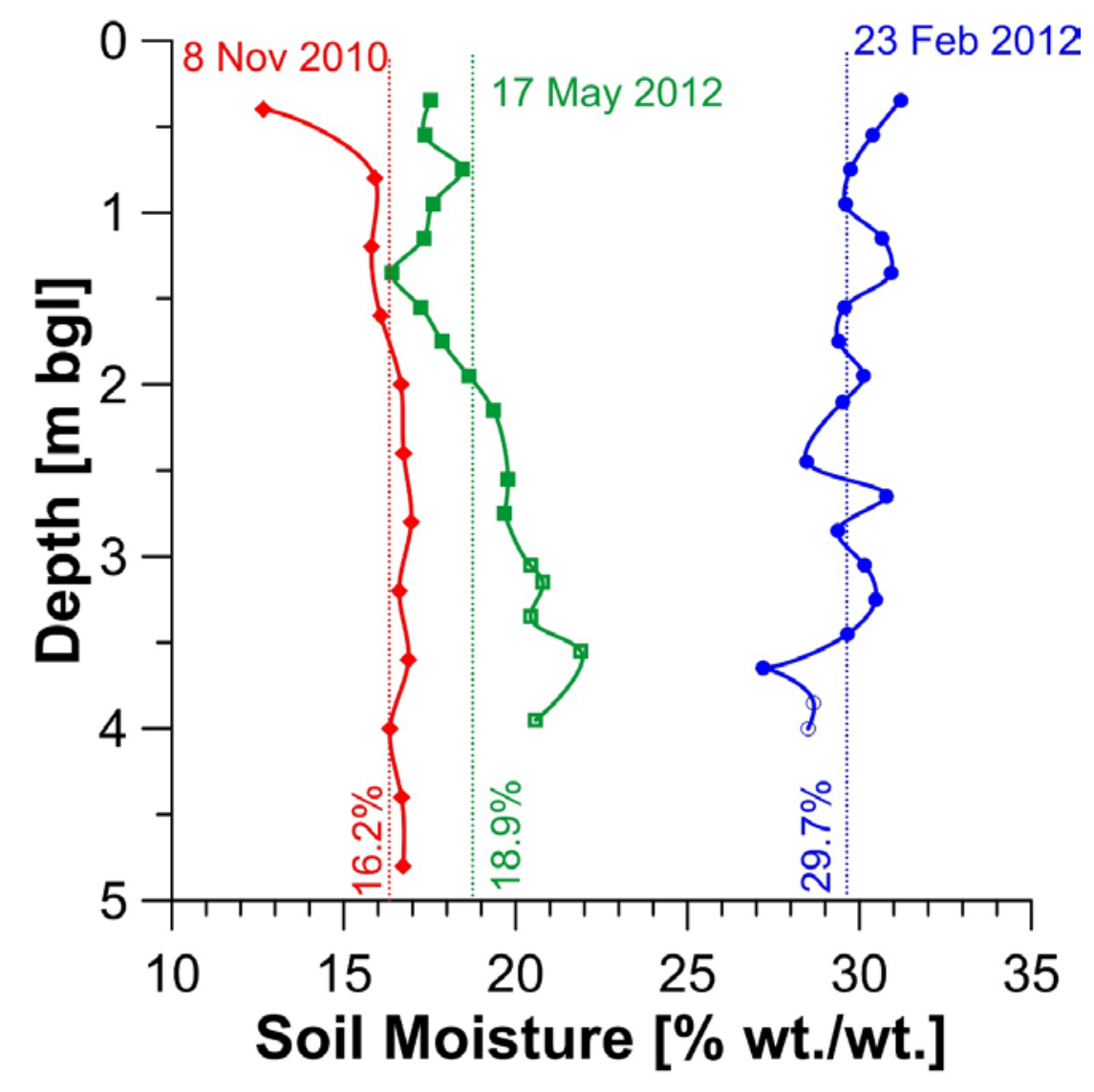

Figure 7. The soil moisture content from repetitive drilling over a 3-year period at CB05 in the central part of the transect (Figs 1, 5 and 6) across the Coolibah Woodlands in the Karijini National Park. The moisture content is the lowest for sampling after a long dry period (November 2010, red line) and the highest for sampling shortly after the cyclone Heidi (blue line). The dashed lines represent mean soil moisture content for each sampling. 


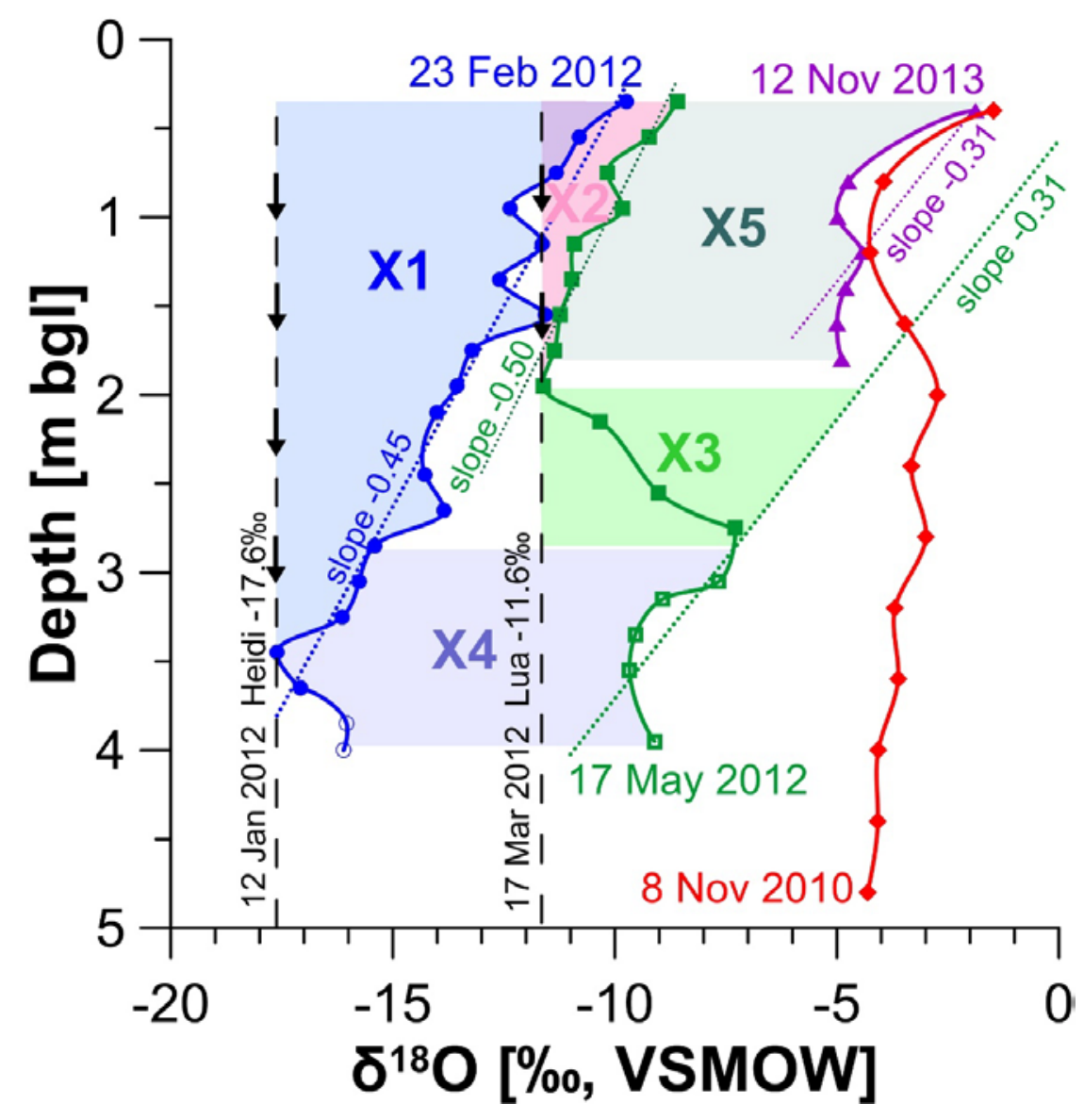

Figure 8. The $\delta^{18} \mathrm{O}$ value of the soil moisture from repetitive drilling over a 3-year period at CB05 (Fig. 1, 5 and 6) in the central part of the transect in the Coolibah Woodlands, the Karijini National Park. Sampling in November 2010 was conducted after a long dry period; dry soil conditions are reflected in the most positive $\delta^{18} \mathrm{O}$ values (red line). The size of the polygons $\mathrm{X} 1$-X5 reflects the evaporative loss from the soil profile (note overlap between X1 and X2). 